\title{
Simulation of the transport, vertical distribution, optical properties and radiative impact of smoke aerosols with the ALADIN regional climate model during the ORACLES-2016 and LASIC experiments
}

\author{
Marc Mallet $^{1}$, Pierre Nabat ${ }^{1}$, Paquita Zuidema ${ }^{2}$, Jens Redemann $^{3}$, Andrew Mark Sayer ${ }^{4,5}$, Martin Stengel $^{6}$, \\ Sebastian Schmidt ${ }^{7}$, Sabrina Cochrane ${ }^{7}$, Sharon Burton ${ }^{8}$, Richard Ferrare ${ }^{8}$, Kerry Meyer ${ }^{5}$, Pablo Saide ${ }^{9}$, \\ Hiren Jethva ${ }^{4,5}$, Omar Torres ${ }^{5}$, Robert Wood ${ }^{10}$, David Saint Martin ${ }^{1}$, Romain Roehrig ${ }^{1}$, Christina Hsu ${ }^{5}$, and \\ Paola Formenti ${ }^{11}$ \\ ${ }^{1}$ Centre National de Recherches Météorologiques, UMR3589, Météo-France-CNRS, Toulouse, France \\ ${ }^{2}$ Rosenstiel School of Marine and Atmospheric Sciences, University of Miami, Miami, FL, USA \\ ${ }^{3}$ University of Oklahoma, Norman, OK, USA \\ ${ }^{4}$ Universities Space Research Association, Columbia, MD, USA \\ ${ }^{5}$ NASA Goddard Space Flight Center, Greenbelt, MD, USA \\ ${ }^{6}$ Deutscher Wetterdienst (DWD), Offenbach, Germany \\ ${ }^{7}$ Laboratory for Atmospheric and Space Physics, University of Colorado, Boulder, CO, USA \\ ${ }^{8}$ NASA Langley Research Center, Hampton, VA, USA \\ ${ }^{9}$ Department of Atmospheric and Oceanic Sciences (AOS), University of California, \\ Los Angeles (UCLA), Los Angeles, CA, USA \\ ${ }^{10}$ Department of Atmospheric Sciences, University of Washington, Seattle, WA, USA \\ ${ }^{11}$ Laboratoire Interuniversitaire des Systèmes Atmosphériques, UMR CNRS 7583, Université Paris Est Créteil et Université \\ Paris Diderot, Institut Pierre Simon Laplace, Paris, France
}

Correspondence: Marc Mallet (marc.mallet@meteo.fr)

Received: 21 November 2018 - Discussion started: 4 December 2018

Revised: 11 March 2019 - Accepted: 12 March 2019 - Published: 12 April 2019

\begin{abstract}
Estimates of the direct radiative effect (DRE) from absorbing smoke aerosols over the southeast Atlantic Ocean (SAO) require simulation of the microphysical and optical properties of stratocumulus clouds as well as of the altitude and shortwave (SW) optical properties of biomass burning aerosols (BBAs). In this study, we take advantage of the large number of observations acquired during the $\mathrm{Ob}$ seRvations of Aerosols above Clouds and their intEractionS (ORACLES-2016) and Layered Atlantic Smoke Interactions with Clouds (LASIC) projects during September 2016 and compare them with datasets from the ALADIN-Climate (Aire Limitée Adaptation dynamique Développement InterNational) regional model. The model provides a good representation of the liquid water path but the low cloud fraction is underestimated compared to satellite data. The modeled total-column smoke aerosol optical depth (AOD) and abovecloud AOD are consistent $(\sim 0.7$ over continental sources
\end{abstract}

and $\sim 0.3$ over the $\mathrm{SAO}$ at $550 \mathrm{~nm}$ ) with the Modern-Era Retrospective analysis for Research and Applications version 2 (MERRA-2), Ozone Monitoring Instrument (OMI) or Moderate Resolution Imaging Spectroradiometer (MODIS) data. The simulations indicate smoke transport over the SAO occurs mainly between 2 and $4 \mathrm{~km}$, consistent with surface and aircraft lidar observations. The BBA single scattering albedo is slightly overestimated compared to the Aerosol Robotic Network (AERONET) and more significantly when compared to Ascension Island surface observations. The difference could be due to the absence of internal mixing treatment in the ALADIN-Climate model. The SSA overestimate leads to an underestimation of the simulated SW radiative heating compared to ORACLES data. ALADIN-Climate simulates a positive (monthly mean) SW DRE of about $+6 \mathrm{~W} \mathrm{~m}^{-2}$ over the $\mathrm{SAO}\left(20^{\circ} \mathrm{S}-10^{\circ} \mathrm{N}\right.$ and $\left.10^{\circ} \mathrm{W}-20^{\circ} \mathrm{E}\right)$ at the top of the atmosphere and in all-sky conditions. Over the conti- 
nent, the presence of BBA is shown to significantly decrease the net surface SW flux, through direct and semi-direct effects, which is compensated by a decrease (monthly mean) in sensible heat fluxes $\left(-25 \mathrm{~W} \mathrm{~m}^{-2}\right)$ and surface land temperature $\left(-1.5^{\circ} \mathrm{C}\right)$ over Angola, Zambia and the Democratic Republic of the Congo, notably. The surface cooling and the lower tropospheric heating decrease the continental planetary boundary layer height by about $\sim 200 \mathrm{~m}$.

\section{Introduction}

Southern Africa is one of the main sources of biomass burning aerosols (BBAs) at the global scale. When the intense smoke plumes are transported over the southeast Atlantic Ocean (SAO), they are able to produce a significant positive (warming) direct radiative effect (DRE, which represents the instantaneous radiative impact of aerosols on the energy balance; Heald et al., 2014) at the top of the atmosphere (TOA) in the shortwave (SW) spectral range and in all-sky conditions (De Graaf et al., 2012, 2014; Feng and Christopher, 2015; Zuidema et al., 2016). Over this specific region, the sign of the DRE is found to be opposite to the cooling effect generally exerted by scattering aerosols at TOA. Based on the combination of satellite observations from A-Train datasets - Moderate Resolution Imaging Spectroradiometer (MODIS), Clouds and the Earth's Radiant Energy System (CERES) and Ozone Monitoring Instrument (OMI) - Feng and Christopher (2015) indicate a regional-averaged instantaneous (i.e., time of observations) DRE of about $+37 \mathrm{~W} \mathrm{~m}^{-2}$ (regional mean; $20^{\circ} \mathrm{S}-10^{\circ} \mathrm{N}$ and $10^{\circ} \mathrm{W}-20^{\circ} \mathrm{E}$ ) for August 2006, with the highest magnitude of the forcing reaching $+138 \mathrm{~W} \mathrm{~m}^{-2}$ at TOA. Significant positive values are also underlined by De Graaf et al. (2012, 2014), who estimate an averaged DRE (August 2006) of about $+23 \mathrm{~W} \mathrm{~m}^{-2}$ near the southern African coast. In parallel, Meyer et al. (2013) report an instantaneous (near local noon for Aqua overpass) regional mean above-cloud radiative forcing efficiency from 50 to $65 \mathrm{~W} \mathrm{~m}^{-2} \mathrm{AOD}^{-1}$ by using their bias-adjusted MODIS cloud retrievals. By using Scanning Imaging Absorption Spectrometer for Atmospheric Chartography (SCIAMACHY) observations and radiative transfer model calculations, De Graaf et al. (2014) further estimate a SW DRE of about $\sim+30 / 35 \mathrm{~W} \mathrm{~m}^{-2}$ over the same domain $\left(4-18^{\circ} \mathrm{S}, 5^{\circ} \mathrm{W}-14^{\circ} \mathrm{E}\right)$ in August and September (2006-2009).

This positive sign (warming) of the DRE is mainly due to the presence of highly reflective stratocumulus $(\mathrm{Sc})$ clouds over the SAO. Although such a positive DRE is occasionally observed over other regions, such as the northeast Pacific during extreme summertime biomass burning events in continental North America (Mallet et al., 2017), the SAO clearly represents the main region at the global scale where such positive forcings can be observed every year at a seasonal timescale. Indeed, this significant radiative forcing is due to the persistent biomass burning emissions over central Africa during the July-August-September-October (JASO) period. Smoke emissions over central Africa are also related to a significant interannual variability, associated with an important increase over the 1979-2015 period (Hodnebrog et al., 2016).

All studies clearly underline the importance of both the aerosol radiative properties of smoke plumes (e.g., aerosol optical depth, AOD; single scattering albedo, SSA), their vertical structures (notably, the localization of smoke vs. Sc clouds; Johnson et al., 2004) as well as the underlying cloud properties (e.g., cloud optical depth (COD), liquid water path (LWP)) on the produced positive SW DRE at TOA. As an example, Feng and Christopher (2015) report a critical COD of 12-20 capable of changing the sign of the DRE from negative to positive (at TOA) for BBA characterized by SSA $\sim 0.91$ and AOD $\sim 1.0$ (at $550 \mathrm{~nm}$ ). In the case of more absorbing smoke (SSA $\sim 0.85$ ), the ranges for critical COD are strongly reduced and reach $\sim 2-4$. Chand et al. (2009) also underline the importance of cloud coverage on the DRE exerted at TOA by smoke over the SAO. In addition, Sakaeda et al. (2011) provided model estimates of regional radiative forcing from direct and semi-direct effects, with important implications on cloud properties (cloud fraction, notably). These complex processes, involving both microphysical and optical properties of BBA and Sc clouds, explain, at least partially, the large difficulty of recent global climate models (GCMs) in reproducing the DRE of smoke over this specific region (Stier et al., 2013).

In that context, it appears crucial to evaluate carefully and constrain both smoke aerosols and Sc properties in GCMs or in their regional configurations (regional climate models, RCMs) before running them over a long time period for radiative budget and climatic considerations. The main objective of this study is to investigate the transport of BBA over the SAO and the vertical layering, as well as optical properties using the ALADIN-Climate (Aire Limitee Adaptation dynamique Développement InterNational) model. In addition, the induced SW DRE at TOA and the possible impact of BBA on the regional (continental) climate are also analyzed. This work has been conducted in the context of several international field campaigns over the SAO region, including the ObseRvations of Aerosols above Clouds and their intEractionS (ORACLES) (Zuidema et al., 2016), the Layered Atlantic Smoke Interactions with Clouds (LASIC; Zuidema et al., 2018), the AErosol RAdiation and CLOuds in southern Africa (AEROCLO-sA) and the Cloud-AerosolRadiation Interactions and Forcing: Year 2017 (CLARIFY2017) projects. More specifically, this study takes advantage of the large number of in situ observations acquired from aircraft and surface measurements during September 2016 for the ORACLES- 1 and LASIC projects. This unique dataset is combined with satellite aerosol and cloud retrievals MODIS, OMI and the Spinning Enhanced Visible and Infrared Imager (SEVIRI) - and reanalysis - the Modern- 
Era Retrospective analysis for Research and Applications, version 2 (MERRA-2), Copernicus Atmosphere Monitoring Service (CAMS) and Monitoring Atmospheric Composition and Climate (MACC) - data.

We focus our analyses on specific properties which are important for studying the radiative effect of BBA over the SAO. For Sc clouds, these are low cloud fraction (LCF), liquid water path (LWP) and COD. For BBA, special attention is paid to AOD, above-cloud AOD (ACAOD), extinction vertical profiles, SSA and SW radiative heating induced by smoke. The DRE at the surface and TOA are estimated and analyzed in addition to climatic implications, especially those exerted by BBA over central Africa. The regional modeling model used in this work is the ALADIN-Climate model (Nabat et al., 2015a, b; Daniel et al., 2019), which has been modified in a recent configuration to better represent smoke aerosols and notably their SW optical properties.

This article is organized as follows. First, details on these recent developments are provided in Sect. 2, along with the design of the ALADIN-Climate simulations. Section 3 reports the complete dataset (satellites, reanalysis, in situ surface and aircraft observations). The analyses of the comparisons between simulated and observed Sc clouds and aerosol properties are presented in Sect. 4. Based on the comparisons, we analyze more specifically the concentration of smoke aerosols over biomass burning sources and during the transport and the altitude of BBA, as well as absorbing properties and induced SW heating rate due to smoke. In addition, the impact of the elevated relative humidity within smoke plumes on optical properties is also investigated in Sect. 4. Finally, Sect. 5 focuses on the analyses of the SW DRE exerted by smoke aerosols at TOA during September 2016, as well as their impact on the continental climate in terms of the surface energy budget (temperature, sensible heat fluxes) and lower troposphere dynamics (planetary boundary layer (PBL), notably).

\section{The regional ALADIN-Climate model}

\subsection{Aerosol scheme}

The recent aerosol scheme (TACTIC, Tropospheric Aerosols for ClimaTe in CNRM-CM) included in the ALADINClimate model accounts for sulfate, organic (OC) and black (BC) carbon, dust and primary sea-salt particles (Nabat et al., 2015b; Michou et al., 2015). The biomass burning emissions from the the sixth phase of the Coupled Model Intercomparison Project (CMIP6) inventory have been used for BC, OC and sulfur gaseous $\mathrm{SO}_{2}$. In the model, mineral dust and seasalt emissions are interactively connected with surface meteorological fields and soil properties (Nabat et al., 2015a). The emission of mineral dust is taken into account following Marticorena and Bergametti (1995) and the current formulation for primary sea spray is based on Schulz et al. (2004).
This model includes advection by atmospheric winds, diffusion by turbulence and surface emissions, as well as dry and wet (in-cloud and below-cloud) removal processes.

For the primary BC and OC species and secondary sulfates, a bulk approach is applied, whereby a fixed aerosol size distribution is assumed for calculating aerosol properties, while for mineral dust and sea-salt particles, a more explicit size representation is used based on three bins for dust and sea salt. The TACTIC scheme assumes an external mixture of the different aerosol species. For specific situations, this could potentially represent a limitation, especially with regard to possible BC mixing (internal/external) state, which can significantly affect SW absorption (Fierce et al., 2016). Knowing that, specific attention is being paid in this study to the simulated absorbing properties (SSA) of BBA, as well as the associated SW heating.

The radiative properties - mass extinction efficiency (MEE), SSA and asymmetry parameter (ASY) - of each aerosol species are calculated for the different spectral bands of the Fouquart and Morcrette radiation scheme (FMR; Morcrette, 1989) and the Rapid Radiative Transfer Model (RRTM; Mlawer et al., 1997), for the SW and longwave (LW) radiation, respectively. Aerosol DRE at the surface and at TOA (in SW and LW spectral ranges and for both clear-sky and all-sky conditions) is diagnosed using a double call (with and without aerosols) to the radiation schemes during the model integration. In addition, the semi-direct radiative forcing, which represents the modifications of the cloud properties and atmospheric dynamics due to absorption of SW radiation by smoke, is derived from the direct effect. In its current version, BBAs are represented by two different tracers (primary BC and OC) with fixed microphysical and radiative properties without any consideration of possible differences between fossil fuel and biomass burning emissions. This hypothesis implies that the radiative hygroscopic properties and $e$-folding time (aging) of carbonaceous species are similar for both anthropogenic and smoke emissions.

\subsection{Smoke radiative properties}

Two tracers have been recently implemented in ALADINClimate describing, respectively, the mass concentration of fresh (less hygroscopic) and aged (more hygroscopic) smoke aerosols, following the methodology presented in Bellouin et al. (2011). This allows to distinguish aerosols from biomass burning and anthropogenic emissions and to monitor specific properties, such as $e$-folding time, hygroscopic and optical properties. In the ALADIN-Climate model, aging from the fresh mode to hygroscopic age is quantified using an $e$-folding time of $6 \mathrm{~h}$ according to Abel et al. (2003). This value is 2 times higher than the one $(\sim 3 \mathrm{~h})$ recently proposed by Vakkari et al. (2018) for southern African savannah. The smoke over the SAO is expected to have aged by 5-7 days (Adebiyi and Zuidema, 2016; Diamond et al., 2018). While studies of the BBA chemical composition and attribution for 
the smoke's optical and hygroscopic properties are still ongoing, preliminary results indicate smoke aging increases its ability to function both as a cloud condensation nucleus and to absorb SW radiation (Zuidema et al., 2018).

For each tracer, dry-state aerosol size distributions are assumed based on lognormal function (Table 1) similar to those implemented in the earth system configuration of the Hadley Centre Global Environmental Model version 2 (HadGEM2ES) (Bellouin et al., 2011). The smoke dry-state refractive indices used to calculate radiative properties are also reported in Table 1 (at $550 \mathrm{~nm}$ ). The values of the real and imaginary refractive indices have been updated using the Aerosol Robotic Network (AERONET) observations obtained by Eck et al. (2013) in Zambia (Mongu Inn station). Although they indicate a pronounced seasonal cycle in the real and imaginary parts of the refractive index from AERONET data, we have used a mean value of 0.03 (at $550 \mathrm{~nm}$ ) for the imaginary component in our Mie calculations (Table 1). This represents an important limitation and the seasonal cycle of smoke-absorbing properties (average SSA at $440 \mathrm{~nm}$ from 0.83 in early July to 0.92 in mid-October, as noted by Eck et al., 2013) is not well represented in ALADIN-Climate. Due to period investigated (September 2016), the implications are expected to be moderate, as smoke is highly absorbing for this month over the continent and SAO (Eck et al., 2013; Zuidema et al., 2018). However, this would be a more severe limitation for simulations encompassing the full biomass burning season.

SW radiative properties have been calculated for the specific wavelength bands of the FMR radiation scheme. The values in the SW spectral ranges are reported in Table 1. At $550 \mathrm{~nm}$ and in dry state, the calculated radiative properties are $4.05 \mathrm{~m}^{2} \mathrm{~g}^{-1}, 0.84$ and 0.51 for the MEE, SSA and ASY for the "fresh" smoke tracer (Table 1). The values for "aged" smoke are, respectively, $5.05 \mathrm{~m}^{2} \mathrm{~g}^{-1}, 0.90$ and 0.58 (Table 1). The MEE used in the model for "aged" smoke is found to be consistent with those reported by Reid et al. (2005). As BBA are known to be hydrophilic (Rissler et al., 2006), the dependence of the radiative properties on relative humidity (RH) has been included for both tracers. This dependence is formulated as described by Solmon et al. (2006):

$\mathrm{MEE}_{\mathrm{wet}}=\operatorname{MEE}_{\mathrm{dry}}(1-\mathrm{RH})^{-\alpha}$,

where $\mathrm{MEE}_{\mathrm{wet}}$ and $\mathrm{MEE}_{\text {dry }}$ are for wet and dry conditions. We have selected a value of 0.26 and 0.15 for the parameter $\alpha$ in order to reproduce the changes of MEE with RH for aged and fresh smoke, respectively. At very high humidity (RH $>99 \%$ ), maximum thresholds of 8.5 and $16.9 \mathrm{~m}^{2} \mathrm{~g}^{-1}$ are considered for fresh and aged smoke, in order to avoid unrealistic values of MEE. In a similar way, we have also implemented a dependence of smoke SSA on RH using the same relationship as (Mallet et al., 2017). The values of $\alpha$ have been fixed to 0.015 (0.02) for aged (fresh) smoke to rep- resent the variations of SSA with RH, as reported in Bellouin et al. (2011).

\subsection{Aerosol and cloud interactions}

"Aerosol-cloud" interactions were represented using a simple parameterization, thereby maintaining the low numerical costs necessary for climate and ensemble simulations. The activation of hydrophilic particles to cloud droplets is not explicitly resolved and the first indirect radiative effect is implemented for hydrophilic sulfates, organic carbonaceous and sea-spray aerosols. This first indirect effect is represented by a simple relationship in ALADIN-Climate relating the mass of hydrophilic aerosols to the cloud droplet number concentration (CDNC) based on the work of Martin et al. (1994). The radiative properties (COD, SSA and ASY) of liquid clouds are calculated in the SW spectral region by the parameterizations proposed by Slingo and Schrecker (1982). In the present work, we do not discuss possible first indirect effects between BBA and Sc clouds, which will be addressed and analyzed in a specific future companion study. The impact of aerosols on liquid clouds via the second indirect effect (precipitation modulation due to the hygroscopic aerosols) is currently under development. In these simulations, the autoconversion rate from water cloud to rain is not sensitive to the aerosol loading and the value of $8.10^{-4} \mathrm{~kg} \mathrm{~kg}^{-1}$ (Smith et al., 1990) is used for the critical cloud water mixing ratio.

\section{Model configuration and data used}

\subsection{Simulation design and important physics options}

The ALADIN-Climate simulations cover the period from 1 August to 31 October 2016. The lateral boundary conditions are provided by ERA-Interim (ERA-INT; Dee et al., 2011). The possible long-range transport of BBA is not forced at the lateral boundary conditions but rather a large domain (latitude: $-37.1^{\circ} \mathrm{S}$ to $09.4^{\circ} \mathrm{N}$; longitude: $-33.4^{\circ} \mathrm{W}$ to $45.4^{\circ} \mathrm{E}$ ) is defined, encompassing the main biomass burning sources. The horizontal resolution of the model is $12 \mathrm{~km}$ with 91 vertical levels (from 1015 to $0.01 \mathrm{hPa}$ ). The land surface is treated using the SURFEX model (Masson et al., 2013). As detailed later, we also use a spectral nudging method described in Radu et al. (2008). The FMR (RRTM) radiative transfer scheme is used to calculate the SW (LW) radiation. Finally, it should be mentioned that the possible impact of BBA reducing the sea-surface temperature (SST) is not treated here and the ALADIN-Climate model is used in a forced mode configuration (with fixed SST). This possible impact of BBA is outside the scope of the present study.

As mentioned previously, the biomass burning emissions from the CMIP6 inventory have been used. These emissions are averaged monthly, reconstructed for the 1997-2015 period from the Global Fire Emissions Database version 4 with 
Table 1. Parameters describing aerosol components used in the ALADIN-Climate model for the two smoke tracers and the resulting optical properties.

\begin{tabular}{lrrrrrrr}
\hline Aerosol species & $r_{0}$ & $\sigma$ & Density & $n / k$ & MEE & SSA & ASY \\
\hline Fresh smoke & 0.10 & 1.30 & 1.350 & $1.50 / 0.03$ & 4.05 & 0.84 & 0.51 \\
Aged smoke & 0.12 & 1.30 & 1.350 & $1.50 / 0.03$ & 5.05 & 0.90 & 0.58 \\
\hline
\end{tabular}

Here, $r_{0}$ and $\sigma$ are the median radius (in $\mu \mathrm{m}$ ) and geometric standard deviation of the lognormal

distribution. Mass density is reported in $\mathrm{g} \mathrm{cm}^{-3}, m$ is the complex refractive index, and MEE and SSA are

the mass extinction efficiency $\left(\mathrm{m}^{2} \mathrm{~g}^{-1}\right)$ and single scattering albedo in dry state and reported at $550 \mathrm{~nm}$.

small fires (GFED4s). The methodology is described by van Marle et al. (2017). In this work, the ALADIN-Climate simulation uses one of the latest historical years (2014) for BC and OC emissions, which cannot allow the model to reproduce precisely the daily aerosol variations especially when they are controlled more by emissions than dynamical aspects. However, it should be noted that the AOD anomaly for September 2014 compared to the 2008-2015 CAMS reanalysis period (Fig. S1 in the Supplement), indicates moderate differences of about $\sim 0.05-0.1$. Additionally, Sayer et al. (2019) found similar above-cloud and total-column AOD over the southern Atlantic Ocean in 2014 and 2016. These suggest that the effect of potential differences between 2014 and 2016 over the biomass burning region is likely to be small. One of the interests of using such methodology is to evaluate the ALADIN-Climate model in its climate configuration, which will be exactly the same as that used to address the radiative and climatic impact of BBA at climatic scale.

Following the study of Petrenko et al. (2017), an adjustment factor of 2.5 is applied to the biomass burning emissions. BBAs are emitted into the first vertical level of the model, without any considerations of pyroconvective processes, as no clear consensus on such processes exists over this region. For example, Labonne et al. (2007) showed that smoke plumes are generally confined in the PBL close to the main biomass burning source regions. In the simulation, fire emissions from the savannah are emitted at the lowest model level, allowing subgrid-scale turbulence mixing through the boundary layer. The diurnal cycle of smoke emission is not taken into account, which could impact the temporal variations of the aerosol loadings (Xu et al., 2016). We assume that the main smoke emissions transported over the SAO are included in the domain defined in Fig. 1. Finally, a climatology is used for organic aerosols produced from vegetation biogenic emission and water vapor released from biomass combustion is not treated in the model.

The BBA mass is known to increase during aging due to the condensation of volatile organic compounds. In the absence of a explicit representation of secondary organic aerosol (SOA) production in ALADIN-Climate, a ratio of particulate organic matter (POM) to primary $\mathrm{OC}$ has been used for artificially representing SOA formation within the smoke plume, when the mass is transferred from the fresh to aged mode in the model. The lack of a complete repre-

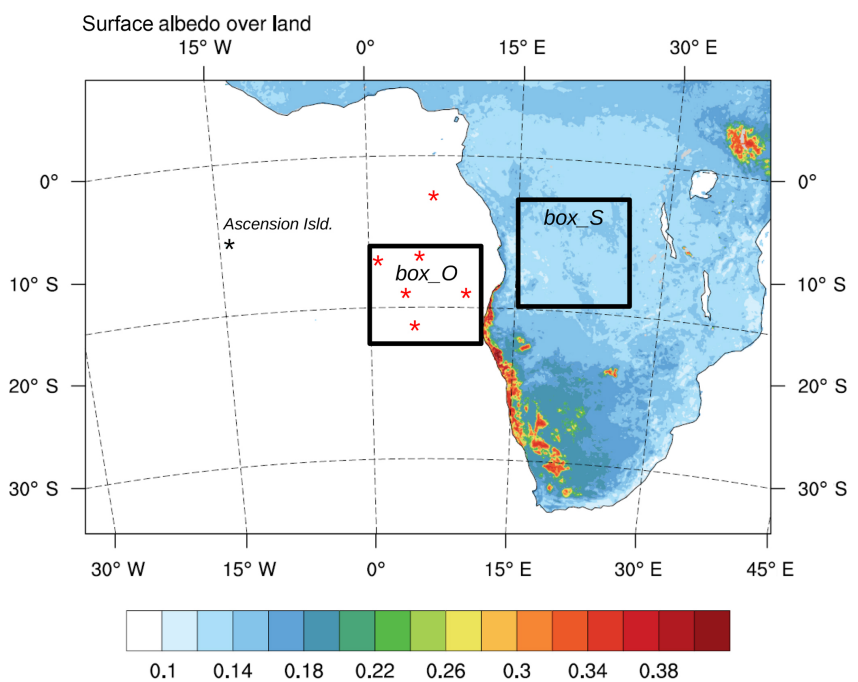

Figure 1. Domain defined for the ALADIN-Climate model simulations (here, the surface albedo is represented). The two different boxes (box_O and box_S) and Ascension Island are indicated. Red stars represent the localization of different profiles studied in the "comparison with HSRL-2 extinction" section.

sentation of SOA in current climate models obviously represents an important source of uncertainties in the estimation of BBA concentration (Johnson et al., 2016). For this ALADINClimate simulation, an average POM / OC ratio of 2.3 is applied (Formenti et al., 2003) based on SAFARI-2000 data. This value is consistent with the recent results obtained by Vakkari et al. (2018) and higher than the one (1.6) retained in HadGEM (Bellouin et al., 2011; Johnson et al., 2016).

Regarding the large uncertainties related to the POM / OC ratio, two sensitivity tests using different $\mathrm{POM} / \mathrm{OC}$ ratios ( 2 and 3) have been performed, showing an important impact of \pm 0.15 on BBA AOD over the continent (Fig. S2 in the Supplement). An additional simulation tested the sensitivity of BBA AOD to the $e$-folding time using the recent value proposed by Vakkari et al. (2018). The results (Fig. S2 in the Supplement) indicate a slight AOD decrease of about -0.05 when averaged over box_S (5-15 $\mathrm{S}, 15-25^{\circ}$ E; see Fig. 1), suggesting in this case a higher sensitivity of AOD to the choice of the POM / OC ratio. 
A total of four ALADIN-Climate simulations (excluding the sensitivity tests only shown in Fig. S2 in the Supplement) are performed. The first one (control run, CTL) does not take BBA into account, while the second simulation (named SMK) includes the direct and semi-direct radiative effects of BBA. As mentioned previously and as absorbing properties of smoke are fixed, the seasonal variations of smoke SSA during the biomass burning season as described in Eck et al. (2013) are not represented in the model. To address this limitation, a simulation (named SMK_SSA) has been performed using less absorbing smoke (SSA of 0.92 at $550 \mathrm{~nm}$ ). Finally, a nudged simulation (named SMK_SN) investigates more specifically the impact of the water vapor transported within the smoke plume on BBA optical properties and the associated SW radiative heating. For the latter, the nudging does not affect PBL, which can be independently influenced by the radiative effects of smoke.

\subsection{Surface, aircraft, satellite and reanalysis dataset}

Different datasets of aerosol and cloud properties from surface, remote sensing and reanalysis have been used for evaluating the ALADIN-Climate simulations. Satellite and reanalysis data are summarized in Table 2.

\subsubsection{LASIC surface observations (Ascension Island)}

SSA (at $529 \mathrm{~nm}$ ) at Ascension Island was estimated from the in situ measurement of the scattering coefficient estimated by a nephelometer and the absorption coefficient deduced from a particle soot absorption photometer (PSAP). The PSAP measurements incorporate an average of the Virkkula (2010) and Ogren (2010) wavelength-averaged corrections and are collected at standard temperature and pressure, with dilution corrections applied. The RH of the air entering the PSAP is estimated to be $25 \%$ or less, while the air entering the nephelometer is measured, with values ranging between $45 \%$ and $60 \%$. Differences in the RH are speculated to bias the SSA higher rather than lower, because drying will reduce the coating thickness on the refractory black carbon, reducing lensinduced enhancement of shortwave absorption. The original nephelometer scattering measurements at $550 \mathrm{~nm}$ are converted to estimated values at $529 \mathrm{~nm}$ using the scatteringderived Ångström exponent. These measurements are also reported in Zuidema et al. (2018). An independent evaluation of the SSA in August-September 2017 using an Aerodyne cavity-attenuated phase shift SSA instrument is consistent with the values reported here (Tim Onasch, personal communication, 2018).

\subsubsection{AERONET retrievals}

Two continental (Mongu Inn and Lubango) and one maritime (Ascension Island) AERONET sites extend local comparisons to the atmospheric column and for different aerosol variables. As described by Dubovik and King (2000),
AERONET allows retrieval of microphysical (volume size distribution) and optical (refractive indexes, SSA, ASY and scattering/absorption optical depth) properties of aerosols, as well as their spectral dependence in the SW spectral range. The uncertainty of retrieved SSA is \pm 0.03 for AOD $(440 \mathrm{~nm})$ $>0.2$ for water-soluble aerosols and for AOD $(440 \mathrm{~nm})>$ 0.5 (zenith angle larger than $50^{\circ}$ ) for desert dust and BBA. For AOD $(440 \mathrm{~nm})<0.2$, the SSA accuracy is $\pm 0.05-0.07$ (Dubovik et al., 2000). In this study, we focus our analyses on level 2 AOD and SSA AERONET products from AERONET version 2.

\subsubsection{Aircraft observations}

\section{Aerosol extinction profiles}

The NASA Langley second-generation High Spectral Resolution Lidar (HSRL-2) has been in operation during ORACLES-1 aboard the NASA ER2. HSRL-2 measures particulate backscatter and extinction at 355 and $532 \mathrm{~nm}$ using the HSRL technique (Shipley et al., 1983) and aerosol backscatter at $1064 \mathrm{~nm}$. All three wavelengths also measure depolarization. The HSRL technique uses a separate filtered channel at each HSRL wavelength that is sensitive to molecular scattering but not aerosol scattering. This channel therefore provides a direct observation of the attenuation of the signal and allows for the direct calculation of aerosol extinction without external constraints or assumptions on the aerosol optical depth or lidar ratio. From this, the vertically resolved particulate extinction is derived by comparison to a molecular density profile from direct measurement or a model. For ORACLES-1, the HSRL-2 retrieval uses molecular density profiles from MERRA-2 (Gelaro et al., 2017). The filtering is accomplished with an iodine gas filter at $532 \mathrm{~nm}$ (Hair et al., 2008) and a density-tuned field-widened Michelson interferometer at $355 \mathrm{~nm}$ (Burton et al., 2018). More information about the instrument, calibrations and algorithms is given by Hair et al. (2008) and Burton et al. (2015, 2018). The vertical resolution for extinction is $315 \mathrm{~m}$ and for backscatter and depolarization is $15 \mathrm{~m}$. The horizontal resolution is $60 \mathrm{~s}$ for extinction and $10 \mathrm{~s}$ for backscatter and depolarization, or approximately $10 \mathrm{~km}$ (extinction) and $1.8 \mathrm{~km}$ (backscatter). The ORACLES HSRL-2 extinction product can be found at https://espoarchive.nasa.gov/archive/browse/ oracles/id8/ER2 (last access: November 2018).

\section{SW heating rate estimates}

Heating rate profiles segregated by absorber (aerosols, water vapor, oxygen) are determined using the spectral information from the Solar Spectral Flux Radiometer (SSFR). SSFR measures upwelling (nadir) and downwelling (zenith) irradiance from 350 to $2100 \mathrm{~nm}$. The zenith light collector is actively leveled, which allows SSFR to obtain spectral irradiance measurements throughout spiral profiles that ex- 
Table 2. Satellite (T: Terra, A: Aqua) and reanalysis data used in this study to analyze aerosols' and Sc clouds' microphysical/optical properties.

\begin{tabular}{lllll}
\hline & Aerosols & Clouds & Spatial/temporal resolutions & Available period \\
\hline MOD06ACAERO & ACAOD & No. & $0.1 \times 0.1^{\circ} /$ daily & Jun-Oct 2000(T)/03(A) - 2019 \\
MODIS-DB & ACAOD & No. & $0.5 \times 0.5^{\circ} /$ daily & $2000(\mathrm{~T}) / 02(\mathrm{~A})-2017$ \\
MODIS-DT/DB & AOD & LWP, COD & $1 \times 1^{\circ} /$ daily & $2000-2019$ \\
OMI & ACAOD & No. & $0.5 \times 0.5^{\circ} /$ daily & $2004-2019$ \\
MISR & AOD & No. & $0.5 \times 0.5^{\circ} /$ monthly & $2000-2017$ \\
SEVIRI & No. & LWP, COD & $0.5 \times 0.5^{\circ} /$ daily & $2004-2015$ \\
ERA-INT & No. & LWP, LCF & $0.7 \times 0.7^{\circ} /$ daily & $1979-2018$ \\
MERRA-2 & AOD by species & No. & $0.5 \times 0.625^{\circ} /$ hourly & $1980-2018$ \\
CAMS & AOD by species & No. & $0.5 \times 0.625^{\circ} /$ hourly & $2008-2015$ \\
MACC & DRE TOA (all sky) & No. & $1.125 \times 1.125^{\circ} /$ daily & $2003-2011$ \\
\hline
\end{tabular}

tend from the top of the aerosol layer to the bottom of the cloud layer. These measurements lend themselves to a new algorithm for retrieving aerosol SSA and ASY from 350 to $860 \mathrm{~nm}$. It uses measurements made during the spiral aircraft descents to separate changes in upwelling, downwelling and net irradiance due to the aerosol layer from those due to the underlying cloud field (Cochrane et al., 2018).

The 4STAR spectral AOD, HSRL-2 extinction profiles and the spectral SSA and ASY retrievals provide the inputs for the heating rate profiles calculated with the libRadtran radiative transfer tool (Mayer and Kylling, 2005). The retrieved intensive aerosol properties SSA and ASY are vertically homogeneous, whereas the spectral extinction coefficient from the merged 4STAR HSRL-2 measurements varies with altitude. The cloud albedo below the aerosol layer is directly measured by SSFR (the reflectance has been estimated around $\sim 800 \mathrm{~m}$ above cloud top), and the atmospheric water vapor profile is determined from in situ measurements. Using these inputs, two calculations of the heating rate profile are done: one with and one without aerosols, and the difference is reported as aerosol heating rate. The accuracy of the calculation is ensured by comparing the calculated irradiance spectrum above and below the aerosol layer with the SSFR measurements. After this step, the heating rate is spectrally integrated over the solar wavelength range $(380-2125 \mathrm{~nm})$.

\subsubsection{Satellite retrievals}

\subsubsection{MODIS and MISR datasets}

The Deep Blue ACAOD retrieved from the MODIS instruments is described in Sayer et al. (2019), which is a slightly updated version of the demonstration algorithm presented in Sayer et al. (2016). In brief, this algorithm performs a multispectral weighted least-squares fit of measured reflectance in four bands across the visible spectral region (centered near $470,550,650$ and $870 \mathrm{~nm}$ ) to simultaneously retrieve ACAOD and the COD. The minimization is performed using optimal estimation. This provides estimates of the uncer- tainty on retrieved parameters, as well as an indicator of how well the retrieval solution is able to fit the measurements. Retrievals where the forward model is expected to be inappropriate, or where the measurements do not constrain the retrieved quantities, are filtered out.

The main updates since Sayer et al. (2016) are twofold. First, the radiative transfer lookup tables have been updated to include dimensions for surface pressure and surface albedo, which improves the realism of the forward model over land. Surface pressure is estimated using terrain altitude, while the surface albedo is taken from a climatology based on the MODIS gap-filled snow-free land albedo dataset (Sun et al., 2017). The second update is that, rather than applying the retrieval to each individual pixel, the pixels are aggregated into $10 \mathrm{~km} \times 10 \mathrm{~km}$ (effective nadir resolution) boxes, chosen to match the resolution of the level 2 MODIS aerosol products. Then, the median reflectance of water cloud pixels within each box is used for the retrieval. Use of median reflectance decreases sensitivity to factors such as 3-D effects or cloud detection errors. Additionally, if a $10 \mathrm{~km} \times 10 \mathrm{~km}$ pixel has a water cloud fraction under 0.75 , it is excluded for the same reason.

The MOD06ACAERO (Meyer et al., 2015) products are also used. These use reflectance observations at six MODIS spectral channels $(0.46,0.55,0.66,0.86,1.24$ and $2.1 \mu \mathrm{m})$ to simultaneously retrieve ACAOD, COD and the cloud effective radius (CER) of the underlying marine boundary layer clouds. Retrievals are performed at the pixel level (here, every fifth native $1 \mathrm{~km}$ pixel) on both Terra (morning) and Aqua (afternoon) MODIS data. Output includes pixel-level estimates of retrieval uncertainty that accounts for known and quantifiable error sources (e.g., radiometry, atmospheric profiles, cloud and aerosol radiative models). Assumptions regarding the cloud forward model and ancillary data usage are consistent with those of the operational MODIS cloud products (MOD/MYD06) (Platnick et al., 2017). Note that both these datasets represent only the partial column AOD, i.e., the AOD above the liquid cloud top, and that ice-phase clouds 
are not processed. In addition, we have also used MODIS Terra and Aqua combined Deep Blue/Dark Target dataset (AOD_550_Dark_Target_Deep_Blue_Combined_Mean _Mean) from the latest collection (6.1) (Sayer et al., 2014) and the Multi-angle Imaging SpectroRadiometer (MISR) (MIL3MAE monthly mean data at $0.5^{\circ}$ resolution; Kahn and Gaitley, 2015) (see Table 2).

\section{OMI dataset}

The OMI sensor, which has been operating since October 2004 aboard the EOS Aura satellite, is a spectrometer with a high spectral resolution (Levelt et al., 2006). OMI offers nearly the daily global coverage with a spatial resolution for the UV-2 and VIS (UV-1) channels ranging from $13 \times 24 \mathrm{~km}^{2}$ at nadir. The OMAERUV_v003 product contains retrievals from the OMI near-UV algorithm (Torres et al., 2007). This algorithm derives a variety of aerosol radiative properties, such as an aerosol index (AI), AOD and ACAOD (uncertainty of $\pm(0.05+30 \%)$ ) for clear-sky conditions. For this study, we have used ACAOD (Jethva et al., 2018) retrieved at $500 \mathrm{~nm}$ (Table 2). An above-cloud aerosol retrieval technique was also applied to the multi-year record of OMI observations to deduce a global product of ACAOD on a daily scale (Jethva et al., 2018).

\section{SEVIRI dataset}

Spatiotemporally highly resolved geostationary satellite observations are taken here from the CLoud property dAtAset based on SEVIRI edition 2 (CLAAS-2; Benas et al., 2017). The CLAAS-2 dataset is based on measurements of the Spinning Enhanced Visible and Infrared Imager (SEVIRI) and was generated and released by the EUMETSAT Satellite Application Facility on Climate Monitoring (CM SAF) as the successor of CLAAS (Stengel et al., 2014). CLAAS-2 includes a variety of cloud properties, of which LWP, COD and CER were used in this study. CLAAS-2 COD and CER are retrieved, similarly to the widely used cloud retrieval method described in Nakajima and King (1990), under the assumption of plane-parallel cloud layers. Lookup tables are precalculated and used to map SEVIRI reflectance at 0.6 and $1.6 \mu \mathrm{m}$ wavelengths to COD and CER as function of satellite-Sun geometries and cloud phase. For liquid clouds, COD and CER are used to calculate LWP following Stephens (1978). The algorithm is initially described in Roebeling et al. (2006) with more details and updates given in Benas et al. (2017), which also report validation exercises. The CLAAS-2 level 2 data are instantaneous data on native SEVIRI resolution with a temporal resolution of $15 \mathrm{~min}$. For this study, the data are projected onto a regular latitude-longitude grid using the nearest-neighbor approach. It should be noted that Sc cloud retrievals could be affected by the presence of BBA over the SAO. Recently, Seethala et al. (2018) indicate that, in the aerosol-affected months of July, August and September, SEVIRI LWP (based on the $1.6 \mu \mathrm{m}$ CER) is biased by $\sim 16 \%$.

\subsubsection{Reanalyses of atmospheric composition}

Two different reanalyses are used for aerosols and clouds (Table 2). The European Centre for Medium-Range Weather Forecasts (ECMWF) reanalysis of global atmospheric composition since 2003 includes five main aerosol species. The first generation of ECMWF reanalysis (Morcrette et al., 2009), issued by the GEMS (Global and regional Earth-System Monitoring using Satellite and in situ data) project, covers the period 2003-2008. MACC is the secondgeneration product and provides improvements in sulfate distributions and has been extended to the 2003-2011 period (Benedetti et al., 2009). Here, we use MACC near-realtime (NRT) daily datasets at $1.125^{\circ}$ resolution of the anthropogenic SW direct effect at TOA in all-sky conditions (Table 2). In addition, we use MERRA-2, generated with version 5.2.0 of the Goddard Earth Observing System (GEOS) atmospheric model and data assimilation system (DAS). The system, the input data streams and their sources, and the observation and background error statistics are fully documented in Rienecker et al. (2011). We rely on the AOD for the different species at $0.5^{\circ} \times 0.625^{\circ}$ spatial resolution (Table 2).

\section{Microphysical and optical properties of Sc clouds and BBA}

\subsection{Sc properties}

The different properties of Sc clouds are analyzed over the box at $10-20^{\circ} \mathrm{S}, 0-10^{\circ} \mathrm{E}$, defined by Klein and Hartmann (1993), referenced in the following as box_O.

\subsubsection{Macrophysical and microphysical Sc properties}

Figure 2a reports the daily mean LWP $\left(\mathrm{g} \mathrm{m}^{-2}\right)$ and LCF, as well as liquid COD, averaged over box_O for September 2016. A reasonable agreement is evident in the LWP between ALADIN-Climate (SMK simulation), SEVIRI and ERA-INT data. The simulated LWP is in the range of ERAINT and SEVIRI data, if slightly less, by $-8 \mathrm{~g} \mathrm{~m}^{-2}$ in the mean compared to ERA-INT. The LWP maxima are also well simulated, especially for 25-28 September, with LWP $\sim 90 \mathrm{~g} \mathrm{~m}^{-2}$. The temporal correlation is about $\sim 0.45$ between ERA-INT and the SEVIRI LWP.

In contrast, an important negative bias of approximately $\sim-20 \%$ is detected in the simulated low cloud fraction compared to ERA-INT values (Fig. 2b). This result is related to a well-known bias (underestimates of low cloud fraction) detected in most GCMs over the Sc regions (Nam et al., 2012). The mean modeled LCF is $57 \%$, compared to $80 \%$ in the ERA-INT dataset. The poor representation of LCF over $S c$ regions remains an open issue outside of the scope of this 

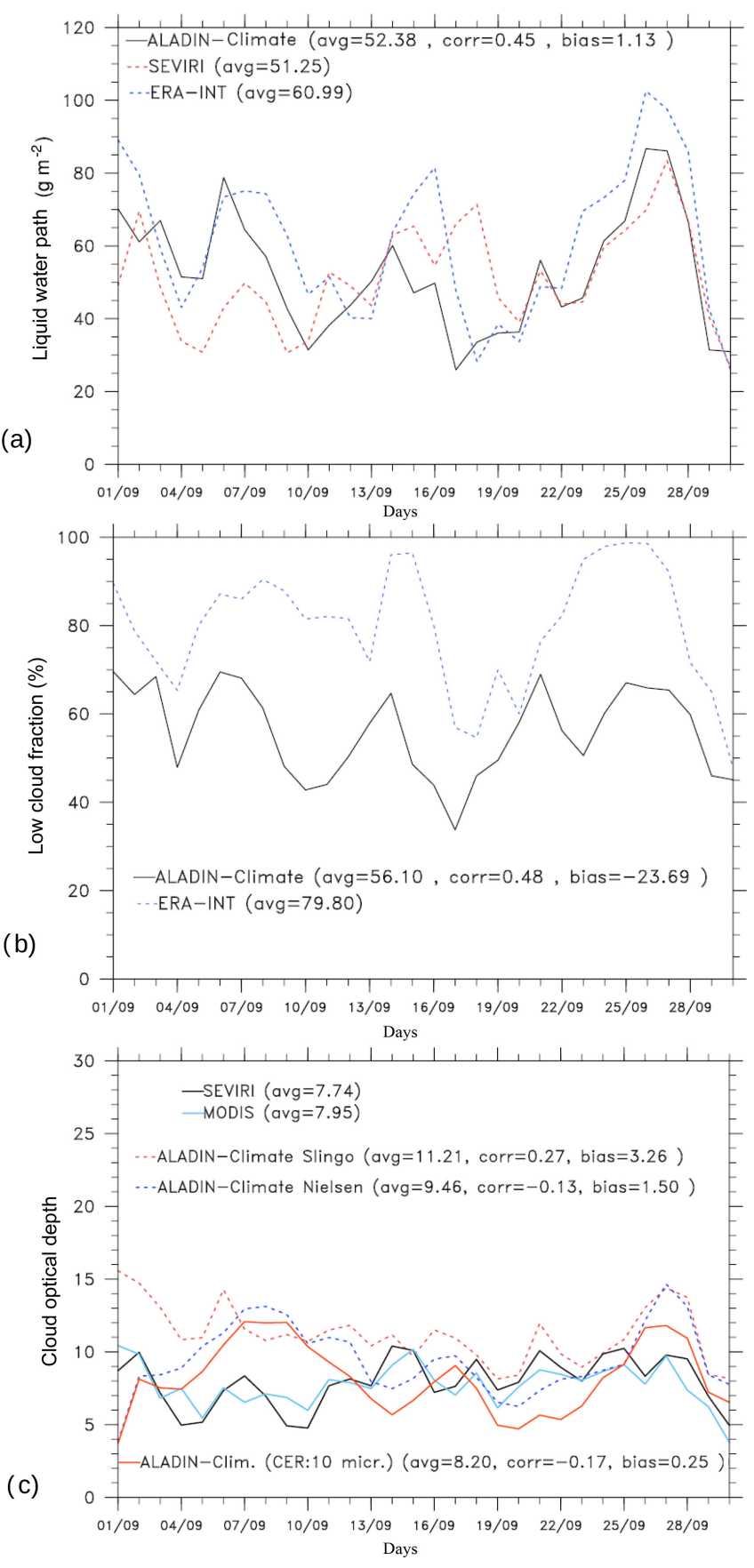

Figure 2. Daily mean Sc properties (LWP, LCF and COD) simulated by ALADIN-Climate and from ERA-INT and SEVIRI data. Values have been averaged over box_O. work. Nevertheless, the analysis and discussions of the following results take into account this underestimate, notably for SW heating rate and the DRE exerted by BBA at TOA.

\subsubsection{Optical Sc properties}

Figure $2 \mathrm{c}$ represents the daily COD estimated by ALADINClimate using the Slingo and Schrecker (1982) and Nielsen et al. (2015) parameterizations, which are used to calculate liquid cloud optical properties at different wavelengths from LWP and CER and different spectral coefficients. This figure also includes an ALADIN-Climate simulation with a fixed CER of $10 \mu \mathrm{m}$, close to the SEVIRI values (Fig. S3 in the Supplement). Retrieved values from MODIS and SEVIRI are also reported in Fig. 2c. The SEVIRI and MODIS Aqua values are consistent with each other, for a mean COD of $\sim 8$ for both instruments. The COD is overestimated by the model in both configurations but especially when the Slingo parameterization is used (average COD value of 11.5). The Nielsen parameterization slightly reduces the bias for a mean COD of 9.5. As the LWP is realistically simulated by the model, this negative bias could be due to errors (underestimates) in the simulated CER by ALADIN-Climate. Our sensitivity test conducted using a fixed CER of $10 \mu \mathrm{m}$ indicates a reduced bias $(+0.25)$. As mentioned previously, the BBA indirect radiative effect is not addressed in this study but is known to be an important issue over the SAO (Costantino and Bréon, 2013; Lu et al., 2017). The indirect radiative effect is also relevant to DRE, as it strongly depends on the albedo of the underlying Sc clouds. The impact of BBA on cloud microphysical properties will be studied in a future work.

\subsection{Biomass burning aerosols}

\subsubsection{AOD over biomass burning source}

Figure 3 compares the (monthly mean) total (clearsky, not above-cloud) AOD simulated by ALADINClimate to those derived from MODIS Terra and Aqua combined Deep Blue/Dark Target dataset (AOD_550_Dark_Target_Deep_Blue_Combined_Mean

_Mean) from the latest collection (6.1) (Sayer et al., 2014) and MISR. The total AOD obtained from the MERRA-2 and CAMS reanalyses is also indicated. All AODs are at $550 \mathrm{~nm}$. Over Angola and Zambia, the model is able to simulate a regional pattern of AOD consistent with the MODIS and MISR retrievals, with AODs of $\sim 0.7-0.9$, even if BBAs are located too far south compared to satellite data. A general good agreement is also observed compared to the CAMS reanalyses, even if the model underestimates AOD over eastern Gabon. Over the continent, significant differences (overestimates) appear clearly compared to MERRA-2. This difference with reanalysis product can be due to the scaling factors applied for biomass burning emissions in the different models. Over the ocean, ALADIN-Climate is found 
to be very consistent with MERRA-2 (AOD $\sim 0.7$ near the Angola coast) but the differences are large compared to the satellite retrievals. The latter AODs are higher $(\sim 0.7-1.0)$, especially for MODIS. It should be mentioned that $50 \%$ of MODIS AOD over the SAO is due to coarse mode according the level 2 retrievals.

In addition, the land-ocean contrast in AOD detected by MODIS and MISR, with lower AODs over the continent and higher AODs over the ocean, is not observed in ALADINClimate. This contrast in AOD is still detected in MERRA2 data, but it is not as large as in the satellite retrievals. It is likely that some of the land-ocean contrast in the satellite data comes from different factors. The first is that the over-land and over-water algorithms are different and may have different biases. The second is that cloud fraction is also significantly higher over the water than over the land, meaning that typically more days of data contribute to the monthly mean over land than over water. Both of these effects could suppress or enhance any real land-ocean contrast in the AOD. Finally, part of the contrast could be due to the presence of sea-spray aerosols, certainly about $\sim 0.1$. As well as continued refinement of AOD retrieval algorithms, it is recommended that future work attempts to quantify the potential magnitude of these sampling effects on land-ocean contrast, which has received comparatively little attention to date. Finally, the satellite data also indicate a larger spatial extent to the aerosol loading over the ocean compared to ALADIN-Climate. This difference could be due to possible overactive aerosol deposition in our simulations. A specific section (Sect. 4.2.2) is dedicated to using ACAOD products for evaluating the model over the ocean.

In order to make comparisons over the continent, a second box (box_S: $5-15^{\circ} \mathrm{S}, 15-25^{\circ} \mathrm{E}$; see Fig. 1) is defined over biomass burning sources. Figure $4 \mathrm{a}$ indicates the daily mean AOD at $550 \mathrm{~nm}$ averaged over box_S from MODIS, MERRA-2 and ALADIN-Climate. There is good agreement, with monthly means of $0.59,0.62$ and 0.49 for MODIS, ALADIN-Climate and MERRA-2, respectively. The model is very consistent with the MODIS retrievals and slightly higher than MERRA-2. Differences between MERRA-2 and ALADIN-Climate may reflect the different model biomass burning emissions. Compared to MODIS, a small mean bias of +0.04 is found in the model over smoke sources. In terms of temporal correlation, the score is worse compared to MODIS. As mentioned previously, this could be due to the time frequency of biomass burning emission (monthly mean emission) imposed in the ALADIN-Climate model. The absence of spectral nudging in the ALADIN-Climate simulation can also explain part of the low temporal correlation, which is clearly higher (0.73) for MERRA-2 data.

Data from three AERONET stations - Mongu Inn (Zambia), Lubango (Angola) and Ascension Island - provide additional AOD evaluation. Figure 5 indicates the daily mean AERONET and ALADIN-Climate (only daytime values) AOD at each station. At Lubango, the model is able to correctly simulate the AOD, except in the beginning of September, when it is overestimated. The maxima (AOD of 0.6) of 20 and 27 September are also well represented by the model. The total monthly mean AOD simulated by ALADIN-Climate (0.41) is consistent with AERONET (0.43), if with a small mean negative bias. Over the Mongu Inn station, the comparisons indicate a more pronounced negative bias (mean value of -0.14 ). This is due to a nearly constant underestimate of total AOD throughout the period of the simulation, leading to a simulated monthly mean of 0.47 , lower than the one observed (0.61). In parallel, the two maxima detected in AERONET data are well captured by the model. The first one, occurring between 18 and 21 September, is simulated too early and its magnitude is overestimated by about $\sim 0.2$. The second (23-29 September) is better reproduced in terms of magnitude $(\sim 1.0)$ but a significant underestimate in its duration is observed. Indeed, the BBA event starts around 22 September in the observations, while it is simulated between 26 and 29 September by the model. Finally, the model is able to correctly simulate the magnitude of AOD along the transport over the SAO to the remote location of Ascension Island (Fig. 5). The simulated monthly mean value (0.26) is comparable to AERONET (0.21) with a small positive bias, primarily because of overestimates during the 6-10 September period. This suggests that winds and aerosol deposition are also well represented. To summarize, the analysis of AOD comparisons demonstrates that the ALADIN-Climate model reasonably simulates the magnitude of AOD during September 2016, even if some biases are detected (possibly due to the monthly mean emissions imposed in the model that do not allow the model to represent some daily variations precisely), especially over the ocean (a negative bias, primarily near the coast) when compared to satellite data.

\subsubsection{ACAOD over the SAO}

Due to the significant presence of Sc clouds over the SAO, the use of satellite clear-sky AOD products as a model evaluation tool is limited. This limitation is overcome with new retrievals of ACAOD from MODIS and OMI, summarized in Table 2. Figure 6 indicates consistent estimates of monthly mean ACAOD between ALADINClimate, MODIS-DB, MOD06ACAERO and OMI. It should be noted that the ACAOD is calculated as the integration of the aerosol extinction from the cloud top to the model top in the ALADIN-Climate model. For all independent estimates, Fig. 6 indicates values of about $\sim 0.4-0.5(550 \mathrm{~nm})$ near the Angola coast. ACAOD then decreases to $\sim 0.2$ over the SAO. ACAOD is underestimated by ALADINClimate over the ocean, especially when compared to the two different MODIS products. Indeed, MODIS-DB and MOD06ACAERO data reveal a larger regional extent over the ocean compared to the model. The ACAOD extent is less 

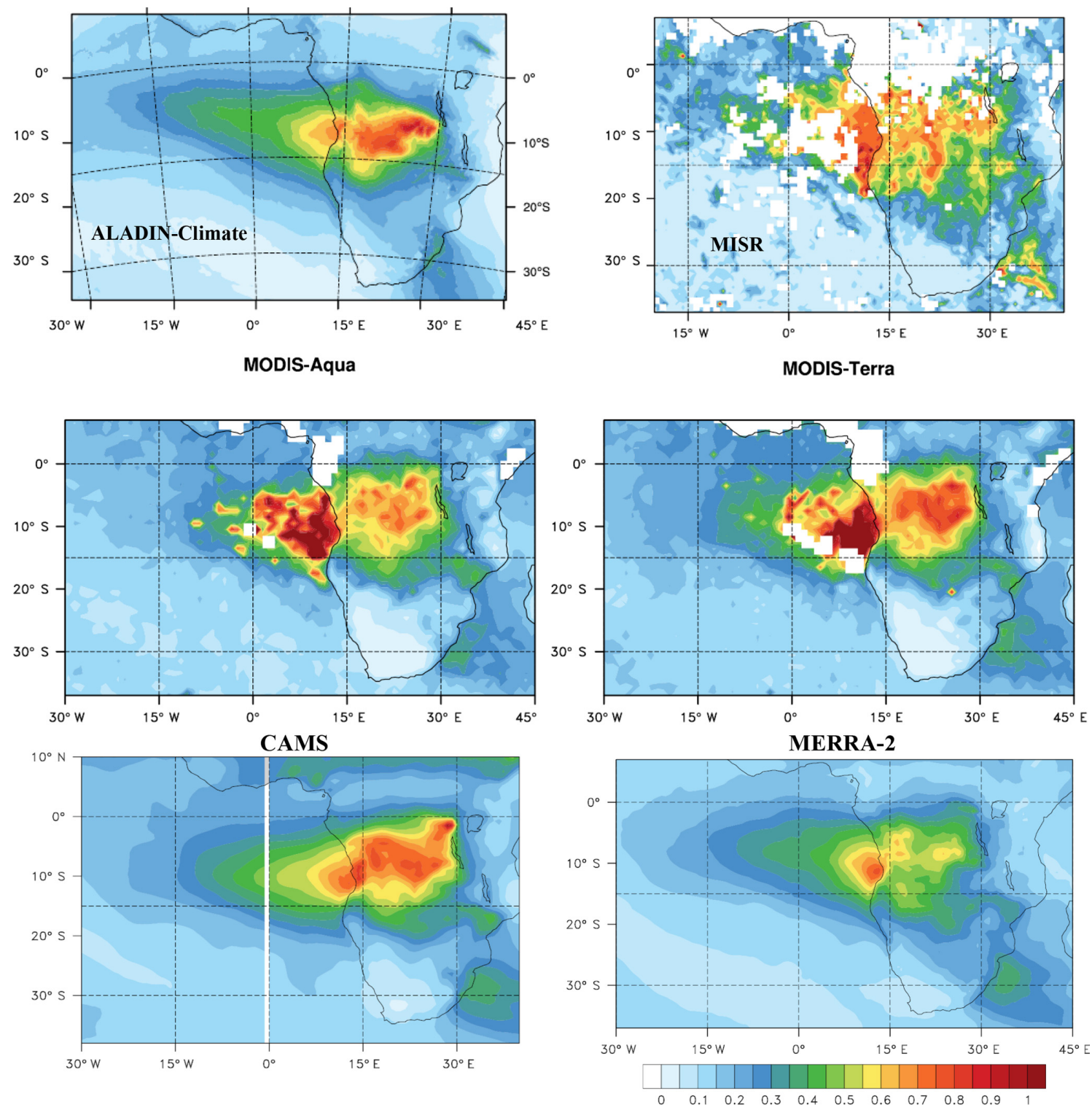

Figure 3. Total monthly averaged total AOD (at $550 \mathrm{~nm}$ ) for September 2016 simulated by ALADIN-Climate (all times used), CAMS, MERRA-2 and derived from the MODIS Terra, Aqua (combined DB/DT products) and MISR sensors.

pronounced in the OMI data, which is thereby more consistent with ALADIN-Climate.

Additional comparisons were performed over box_O using MODIS-DB products. Figure $4 \mathrm{~b}$ indicates daily mean model ACAOD obtained for the SMK and SMK_SN (not discussed in this part) simulations and MODIS-DB. The monthly mean ACAOD is underestimated by the model (SMK configuration; dotted red line) with a mean value of 0.20 (at $550 \mathrm{~nm}$ ), 0.06 less than MODIS-DB (0.26). The ALADIN-Climate simulation underestimates two maxima observed by MODIS-DB, around 3-5 and 20-24 September, explaining part of the negative bias $(-0.06)$ in the SMK simulation. For the rest of the time period, we observe a realistic estimation of ACAOD by the model. It should be mentioned that additional analyses of the simulated ACAOD are also discussed in Shinozuka et al. (2019) for different boxes defined in the ORACLES-1 program, indicating similar results with an underestimate of ACAOD. As for AOD, ALADINClimate is shown here to simulate realistically the concentration of aerosols transported above clouds over the SAO. This allows to address the SW DRE exerted by BBA at TOA during ORACLES, after investigating the vertical structure (Sect. 4.2.3) and SW absorbing properties (Sect. 4.2.4). 

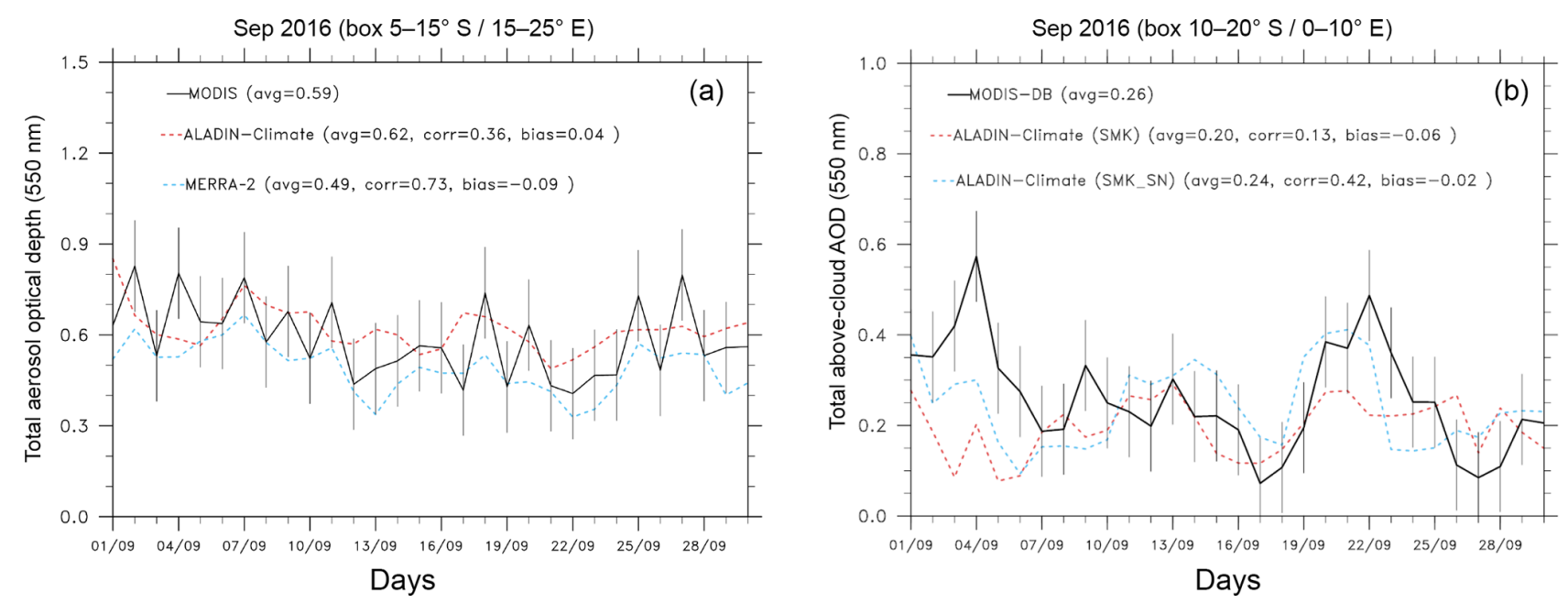

Figure 4. Total daily mean AOD (at $550 \mathrm{~nm}$ ) averaged over box_S $\left(5-15^{\circ} \mathrm{S}, 15-25^{\circ} \mathrm{E}\right)$ from the ALADIN-Climate model (10:30 and 13:30 UTC outputs are used), MERRA-2 and derived from MODIS Aqua DT data (a). Daily mean ACAOD (at 550 nm) estimated from the MODIS-DB satellite and two different configurations of the ALADIN-Climate model (SMK and SMK_SN) averaged over box_O (0-10 ${ }^{\circ}$ N, $\left.10-20^{\circ} \mathrm{E}\right)(\mathbf{b})$. Uncertainties related to DT AOD and DB ACAOD are also indicated.
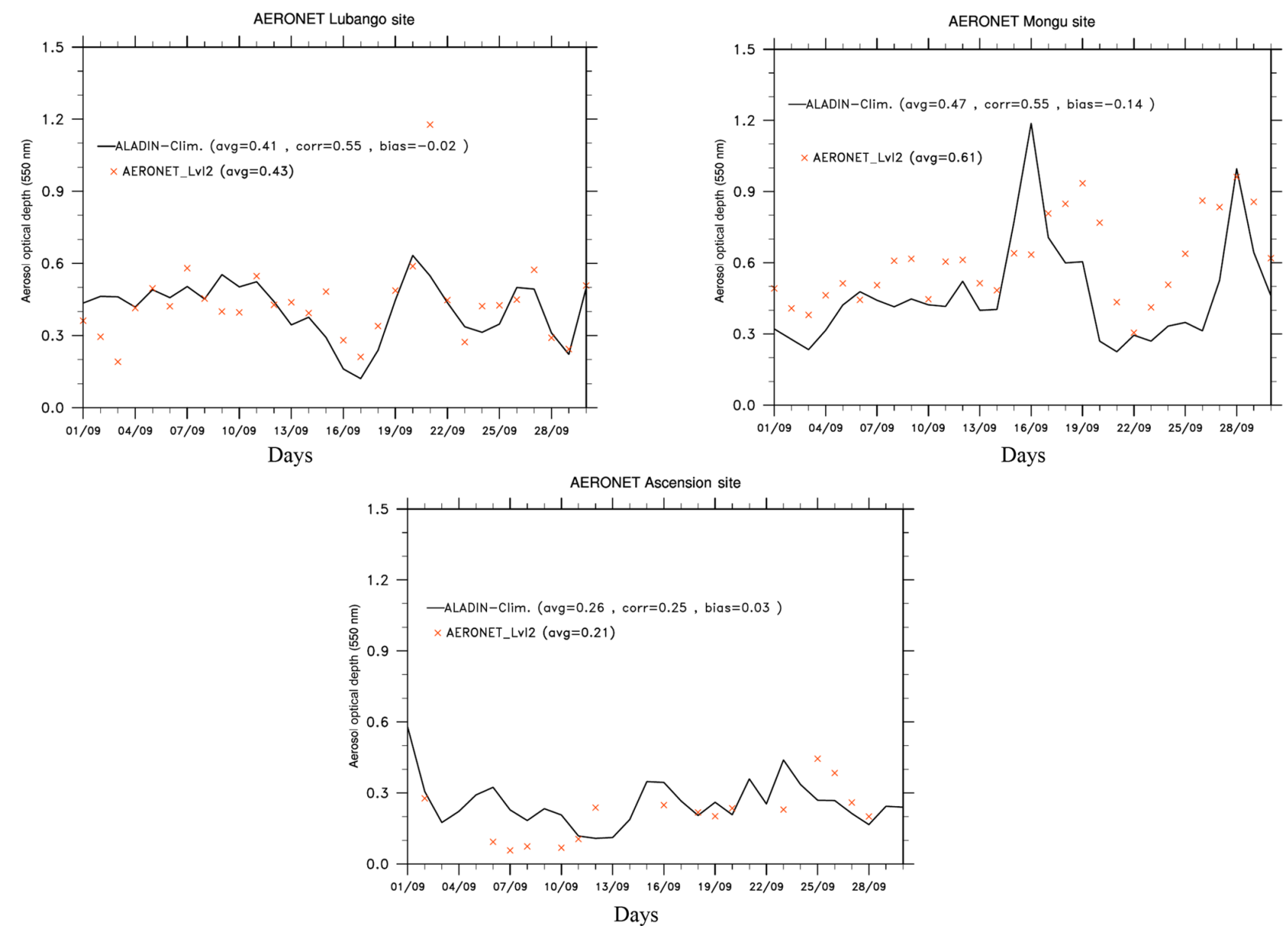

Figure 5. Comparisons of daily mean total AOD obtained at the Lubango, Mongu Inn and Ascension Island AERONET stations (daytime model outputs only) for September 2016. 

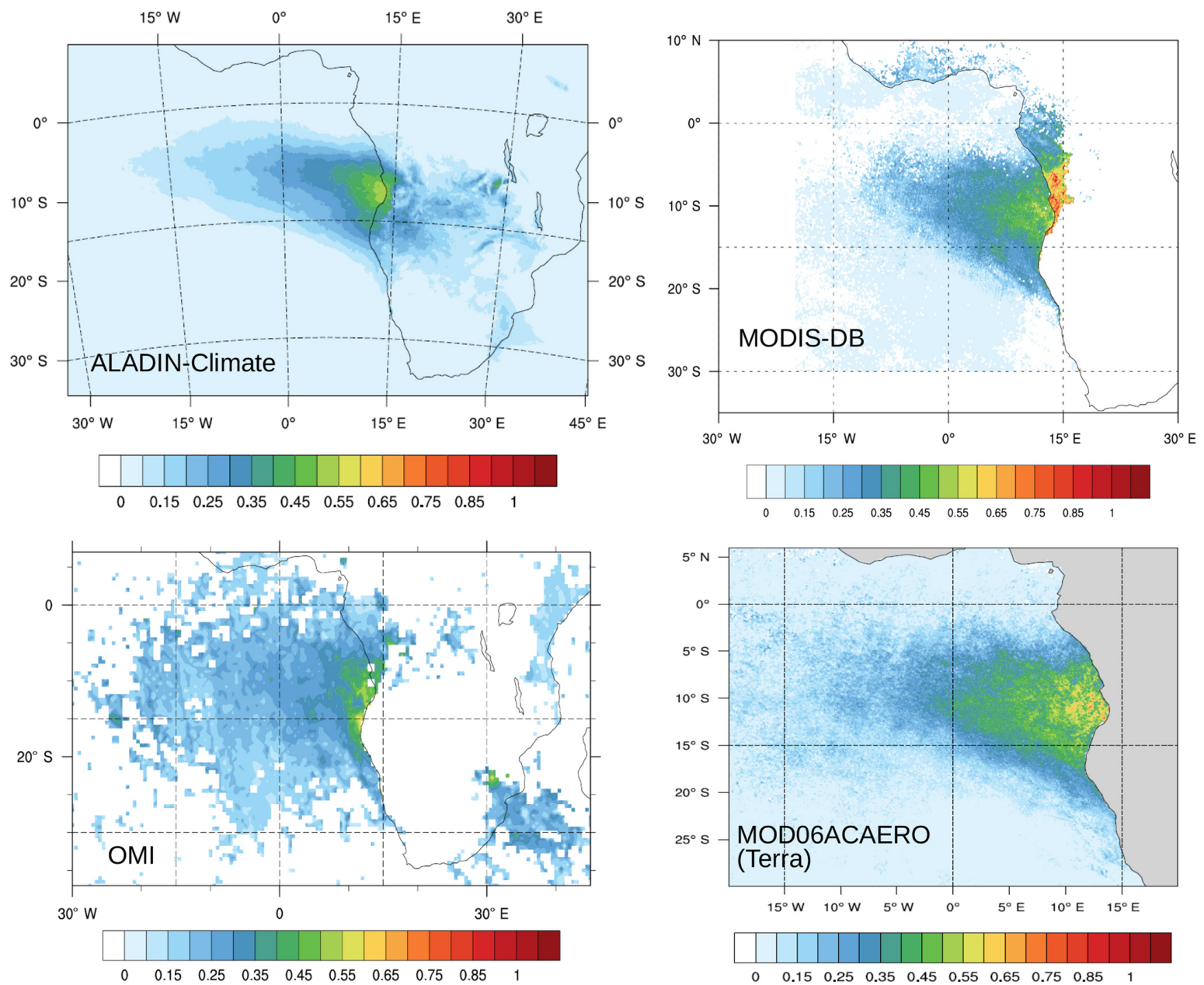

Figure 6. Total monthly averaged ACAOD (at $550 \mathrm{~nm}$ ) for September 2016 simulated by the ALADIN-Climate (10:30 and 13:30 UTC outputs only are used) model and derived from MODIS (Deep Blue and Meyer retrievals) and OMI instruments.

\subsubsection{BBA vertical structure}

\section{ALADIN-Climate extinction vertical profiles}

The vertical distribution of the modeled BBA extinction is analyzed over the continent and SAO in Fig. 7 as the monthly mean extinction vertical profiles (at $550 \mathrm{~nm}$ ) for two different transects at latitudes of 8 and $15^{\circ} \mathrm{S}$. For both transects, the highest extinctions are identified over the continent, close to biomass burning sources, with extinctions $\sim 0.2 \mathrm{~km}^{-1}$. The amplitude of BBA extinction coefficient (Fig. 7b, d) decreases during the transport, reaching values of $\sim 0.05-0.10 \mathrm{~km}^{-1}$ (at 8 and $15^{\circ} \mathrm{S}$, respectively) for longitudes near $0^{\circ}$. For both profiles, the top of the smoke plume is around $\sim 5000 \mathrm{~m}$ over the continent in the simulations, consistently with the altitude of the top plume reported by Das et al. (2017) from Cloud-Aerosol Lidar with Orthogonal Polarization (CALIOP) observations. This analysis would suggest that injection heights are not that important in this region and aerosols are mainly lofted by convection over the biomass burning sources.

Over the SAO, two different well-distinguished aerosol layers are simulated: the first one mainly located in the marine boundary layer (MBL) and mostly due to primary sea-spray aerosols, and a second BBA layer located above, between 2000 and $4000 \mathrm{~m}$. The top of the marine aerosol plume is simulated around $\sim 1000 \mathrm{~m}$ and is separated from the smoky layer by a clean atmospheric layer, especially at $15^{\circ} \mathrm{S}$, characterized by extinction near $\sim 0.05 \mathrm{~km}^{-1}$. For both transects, the top of the smoke plume decreases from $10^{\circ} \mathrm{E}$ to $10^{\circ} \mathrm{W}$, starting around $\sim 5000 \mathrm{~m}$ near the coast to reach $\sim 4000 \mathrm{~m}$ at $10^{\circ} \mathrm{W}$. This BBA stratification over the SAO is consistent with the vertical structure reported by Das et al. (2017) for latitudes comprised between 0 and $10^{\circ} \mathrm{S}$. Indeed, they report a transport of smoke that mainly occurs between 2000 and $4000 \mathrm{~m}$ over the SAO, contrary to the different models used in this study, which both indicate a more pronounced decline of the altitude of BBA during the trans- 

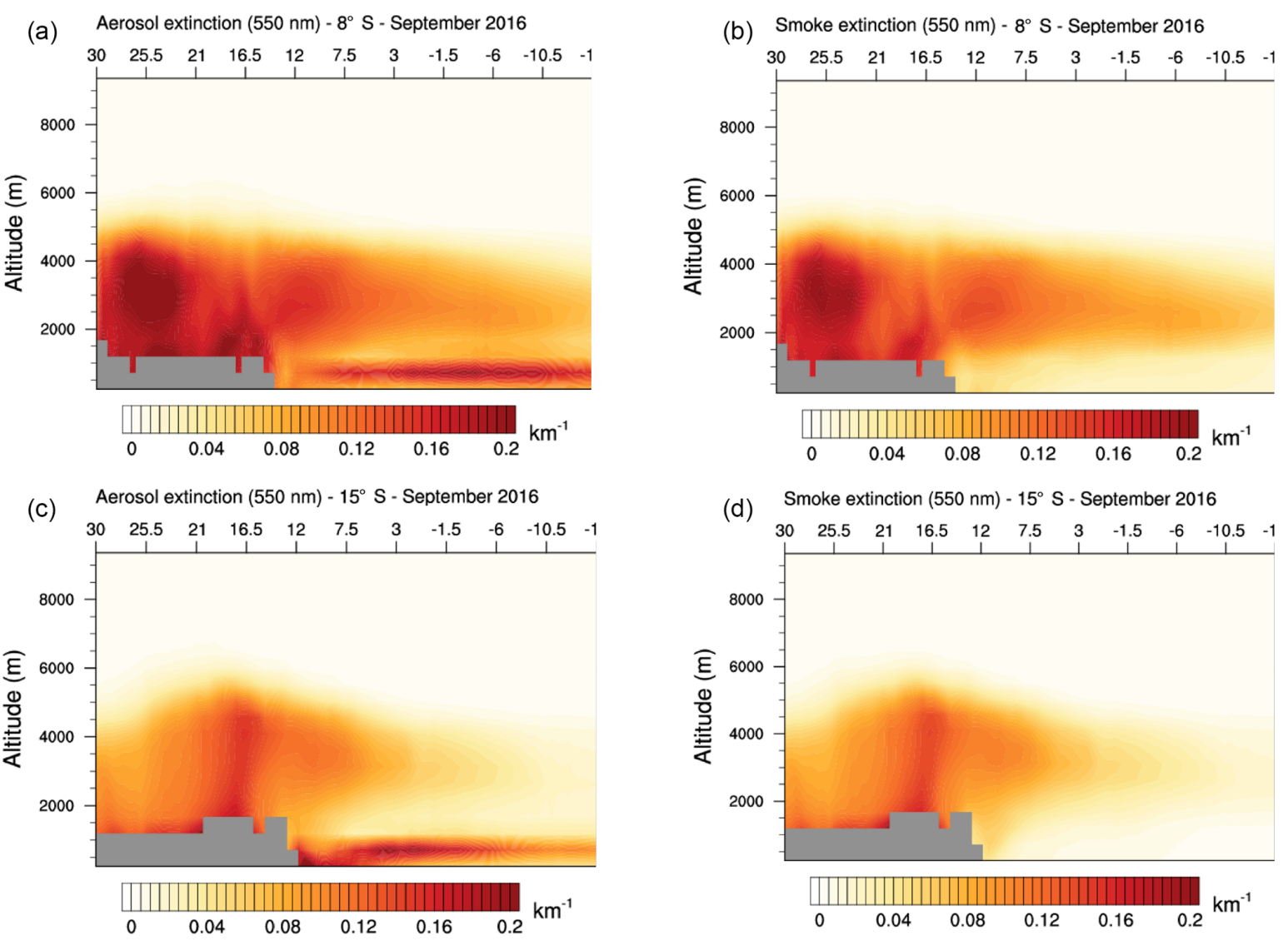

Figure 7. Monthly averaged vertical profiles of the total aerosol (a) and smoke (b) extinction coefficient (at $550 \mathrm{~nm}$ ) simulated by the ALADIN-Climate model for two transects at latitudes of 8 and $15^{\circ} \mathrm{S}$. Longitudes are between $30^{\circ} \mathrm{E}$ and $11.5^{\circ} \mathrm{W}$.

port. This result is also consistent with a previous study from Haywood et al. (2003) over this region.

The elevated plume is mainly composed by BBA characterized by a decrease in extinction (mainly due to a decrease of BBA concentration) during the transport from $0.15 \mathrm{~km}^{-1}$ (at $15^{\circ} \mathrm{E}$ ) to $0.08 \mathrm{~km}^{-1}$ (near $0^{\circ}$ ) for the transect at $8^{\circ} \mathrm{S}$. Such extinction values are consistent with those reported by Das et al. (2017), who indicated CALIOP extinction around $\sim 0.1-$ $0.15 \mathrm{~km}^{-1}$ over the SAO (for latitudes between 0 and $10^{\circ} \mathrm{S}$ ). The extinction due to BBA is negligible in the simulation for longitudes higher than $\sim 10^{\circ} \mathrm{W}$, especially for the transect at $15^{\circ} \mathrm{S}$. For both transects reported in Fig. 7a and c, significant extinctions are simulated within the MBL, with values of about $\sim 0.2-0.25 \mathrm{~km}^{-1}$ mostly due to the presence of primary sea-spray aerosols. Figure 7 indicates the highest values at $8^{\circ} \mathrm{S}$ compared to $15^{\circ} \mathrm{S}$.

Based on the transects, no favorable conditions are identified allowing an efficient mixing of BBA within the MBL during the transport of aerosols over the SAO. Such results are found to be different from the schematic view of Gordon et al. (2018), who proposed that an efficient mixing of smoke only occurs around $0^{\circ} \mathrm{E}-10^{\circ} \mathrm{W}$ within the MBL. This could limit the possible impact of BBA on cloud droplet con- centrations and Sc properties. In the ALADIN-Climate simulations, smoke aerosols primarily remain above the MBL during transport, with little vertical mixing. For this reason, in the model, the impact of BBA on the Sc microphysical/optical properties will be primarily through the semidirect radiative effect.

\section{Comparison with HSRL-2 extinction}

Aerosol extinction coefficients derived at three different wavelengths $(355,532$ and $1064 \mathrm{~nm})$ by the HSRL-2 instrument permit local 1-D comparisons with ALADIN-Climate simulations. In addition to evaluating the simulated extinction vertical profiles, the spectral dependence of the modelcalculated extinction can also be evaluated. Figure 8 reports the extinction vertical profiles for three different days (12, 22 and 24 September), as well as RH profiles obtained from MERRA-2 and ALADIN-Climate (dotted black and solid lines, respectively). Those specific days have been chosen to represent different locations within box_O (Fig. 1). The vertical profile of CF simulated by ALADIN-Climate (dotted yellow line) is also included in Fig. 8. It should be mentioned that the wavelengths of ALADIN-Climate are not exactly the same as those from HSRL-2, especially for the UV spectral 
band (355 and $440 \mathrm{~nm}$, respectively). In addition and due to the significant CF, HSRL-2 data are not necessarily available near the surface and remain above cloud top $(\sim 2000 \mathrm{~m})$ in most cases.

For 12 September, our simulations indicate that the vertical structure of the BBA plume (dashed red, purple and blue lines) is not well represented in the model even though both the model and HSRL-2 place most of aerosol above the MBL. At both times (11:00 and 13:00 UTC), the aerosol extinction coefficients simulated by ALADIN-Climate are overestimated (underestimated) for altitudes between 1500 and $3000 \mathrm{~m}$ (3000 and $6000 \mathrm{~m})$. This compensation of errors leads to a consistent averaged (between 1500 and $6000 \mathrm{~m})$ integrated extinction in the simulation $\left(0.07 \mathrm{~km}^{-1}\right.$ at $550 \mathrm{~nm})$ compared to HSRL-2 observations $\left(0.06 \mathrm{~km}^{-1}\right)$ at 13:00 UTC but but significant underestimates at 11:00 UTC $\left(0.05\right.$ and $0.13 \mathrm{~km}^{-1}$, for ALADIN-Climate and HSRL-2, respectively). In addition, we observe important biases in the simulated RH, especially at 11:00 UTC between the surface and $3000 \mathrm{~m}$ (positive bias) and (negative bias) above $3000 \mathrm{~m}$, which could partly explain the extinction biases.

For 22 and 24 September, Fig. 8 indicates that the altitude of the smoke plume over the SAO is realistically represented by ALADIN-Climate, especially for the plume located between 3000 and $6000 \mathrm{~m}$. However, a second aerosol layer, which is observed from HSRL-2 between 2000 and $3000 \mathrm{~m}$ for 24 September at 11:00 UTC (Fig. 8e), is absent in ALADIN-Climate and simulated below (between 1000 and $2000 \mathrm{~m}$ ). For the same day, at 12:00 UTC (Fig. 8f), similar conclusions are obtained with a maxima at $\sim 3500 \mathrm{~m}$ which is well simulated by ALADIN-Climate but the second plume (observed around $\sim 2000-2500 \mathrm{~m}$ from HSRL-2) is totally absent in the model. For both days, Fig. 8 reveals that the magnitude of the simulated extinction is generally underestimated compared to HSRL-2, true at each wavelength. As an example, for 24 September at 11:00 UTC (Fig. 8a), the local maxima $\left(\sim 0.30 \mathrm{~km}^{-1}\right)$ derived by the HSRL-2 instrument at $5000 \mathrm{~m}$ are significantly lower $\left(\sim 0.15 \mathrm{~km}^{-1}\right)$ in the model. This is also observed for the second aerosol plume at $\sim 2500 \mathrm{~m}$ for that day. Such conclusions can be drawn for all cases (12, 24 and 26 September), with a negative (mean) bias (indicated only at $550 \mathrm{~nm}$ and for the whole atmospheric column) of between -0.01 and $-0.08 \mathrm{~km}^{-1}$. This could be attributed to incorrect smoke emissions, $e$-folding time, POM / OC ratio, optical properties (especially the mass extinction efficiencies) of BBA, as well as the different parameterizations used for representing hygroscopic properties of aged smoke. In Sect. 4.3, specific attention is paid to the impact of RH transported within the smoke plume on BBA extinctions.

\subsubsection{BBA (SW) absorbing properties and heating rate}

\section{Absorbing properties at the biomass burning source}

The magnitude and the sign of the DRE of BBA exerted over the SAO is highly sensitive to the smoke SSA. The monthly mean (whole-column-integrated) SSA (for the fine aerosols) simulated by ALADIN-Climate for September 2016 (Fig. S4 in the Supplement) indicates values of about $\sim 0.85$ (at $550 \mathrm{~nm}$ ) over a large part of the subcontinent. SSA increases near the coast $(\sim 0.89-0.90)$ and during transport over the SAO ( 0.92 to 0.95$)$. Local comparisons at the two continental AERONET stations (Mongu Inn and Lubango; Fig. S4 in the Supplement) reveal good agreement between the simulated and observed SSA, characterized by low bias of about $+0.01 /-0.02$. A larger negative bias is observed and documented at the Lubango site. However, the day-to-day variability is not represented in the model and SSA is nearly constant $(\sim 0.83-0.84)$ in the simulation. As an example, the lowest values $(\sim 0.79-0.80 \pm 0.04)$ detected by AERONET are absent in the model. The same conclusion is obtained for the highest values derived from observations, especially at Lubango (Fig. S4 in the Supplement). However, such results indicate the ability of the model at reproducing absorbing properties of BBA close to biomass burning emissions with limited bias $(-0.02 /+0.01)$.

\section{Absorbing properties over the SAO}

The model comparison to in situ surface-based SSA values at Ascension Island reveals more discrepancy. Figure 9 shows the daily mean SSA obtained at the surface from in situ observations and calculated with ALADIN-Climate at two different altitudes $(0.2$ and $3 \mathrm{~km})$. The model is not able to reproduce the low values (mean of 0.87 ) observed at the surface. Indeed, near the surface, the simulation indicates a simulated SSA of nearly 1 for all of the September 2016 period. The model MBL optical properties are mainly controlled by primary marine aerosols (see Fig. 7) leading to SSA close to unity. This highlights also that the mixing of BBA within the MBL is possibly underestimated in the model, although LASIC observations also show little smoke is present at the surface in September (Zuidema et al., 2018). The LASIC site is also located on the remote windward side of the island and is not affected by local sources, of which there are few to begin with (no trash burning on the island).

It should be noted that the low values of SSA obtained at Ascension Island could reflect long-term aging processes for the BBA, which are not currently included in ALADINClimate. One indication that the aerosol sampled at the LASIC is aged is through the parameters $f_{44}$ and $f_{60}$ (the fraction of the organic aerosol mass spectrum signal at $m / z 44$ and 60, respectively), in the data from the Aerosol Chemical Species Monitor (Alison Aiken, personal communication, 2018). The LASIC $f_{44}$ and $f_{60}$ values of approximately 
(a)

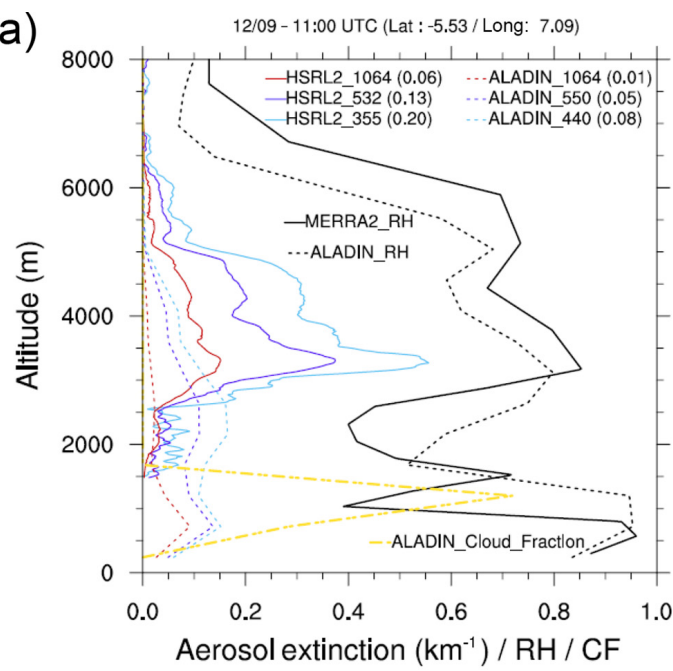

(c)

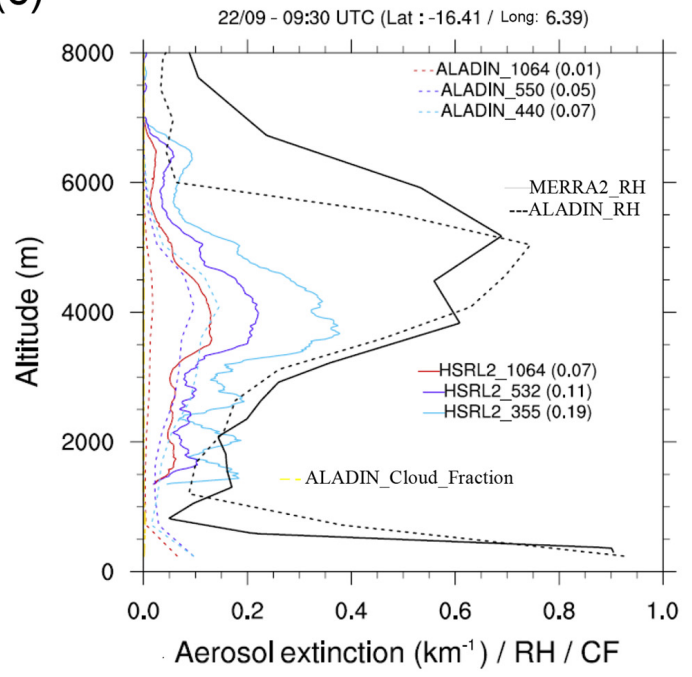

(e)

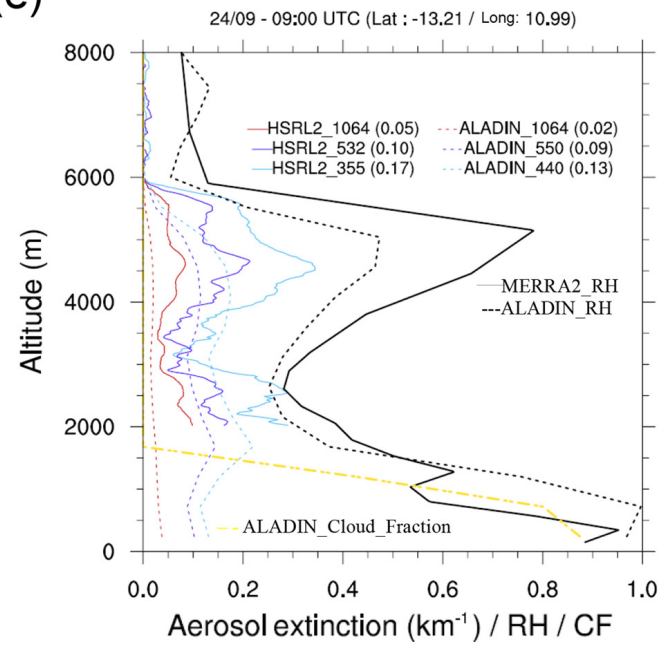

(b)

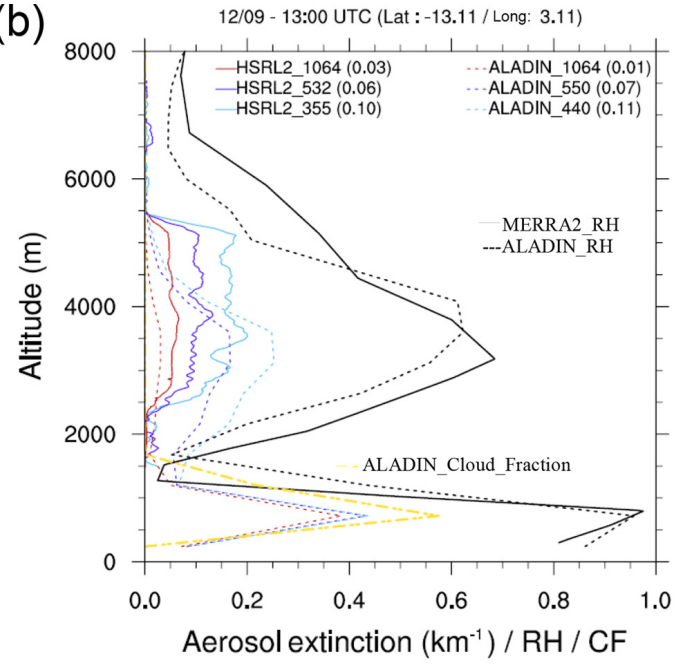

(d)

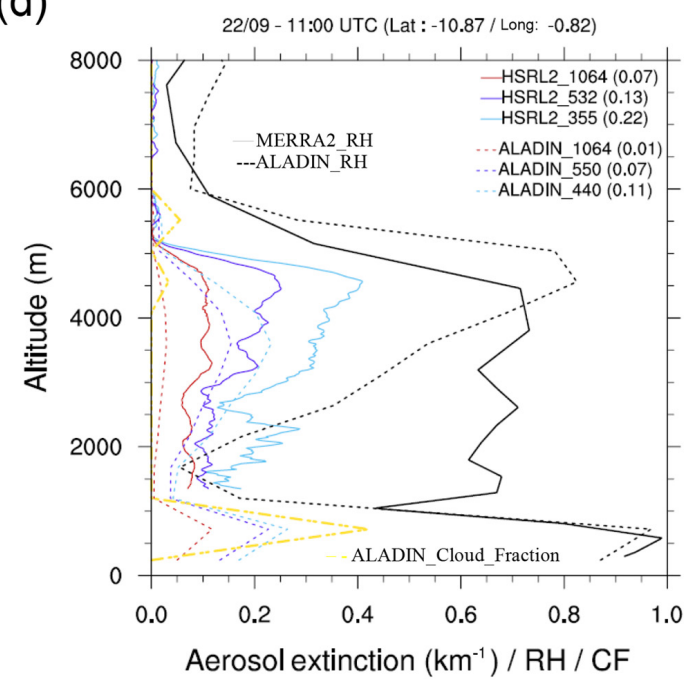

(f)

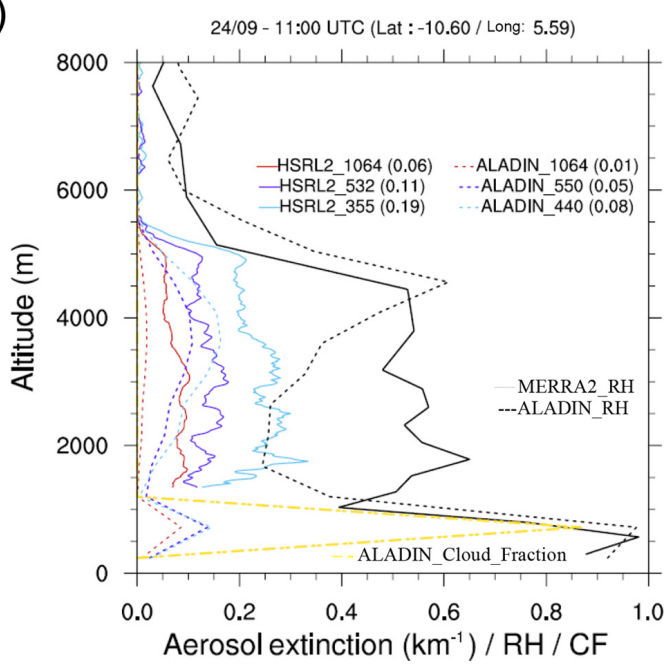

Figure 8. Vertical profiles of aerosol extinction coefficient (in $\mathrm{km}^{-1}$ ) at three different wavelengths from ALADIN-Climate and HSRL-2 instrument (red: $1064 \mathrm{~nm}$; purple: $550 \mathrm{~nm}$; blue: $440 \mathrm{~nm}$ ), associated with the mean values (note that the wavelengths are not exactly similar, especially in ultraviolet). Also reported are the vertical profiles of RH simulated by ALADIN-Climate (dotted black) and MERRA-2 (black), as well as the ALADIN-Climate cloud fraction (dotted yellow). 


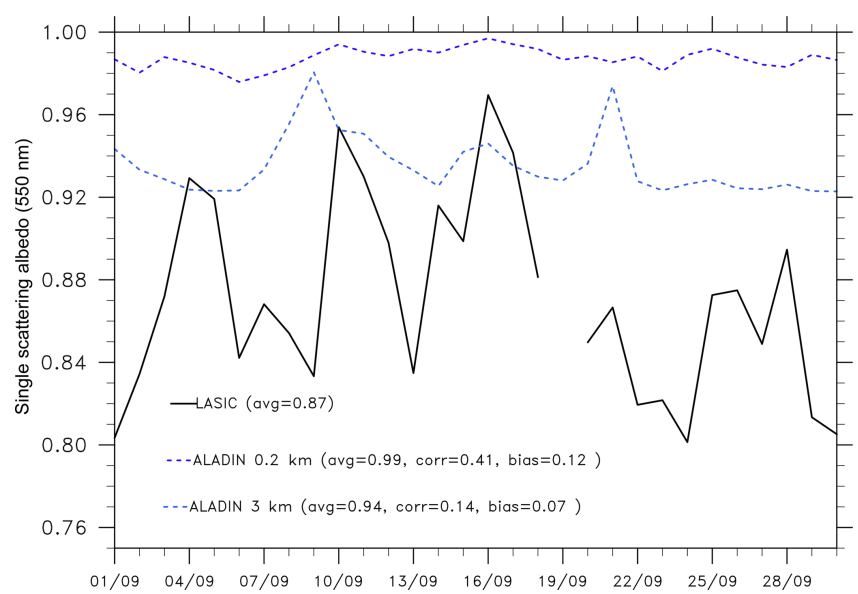

Figure 9. Daily mean in situ SSA estimated at the surface at Ascension Island (LASIC) and simulated with the ALADIN-Climate model at two different altitudes $(0.2$ and $3 \mathrm{~km})$.

0.2 and 0.002 , respectively, are characteristic of highly aged aerosols (Cubison et al., 2011). This chemical process could increase the absorbing efficiencies of BBA (Fierce et al., 2016) due to the "lensing" effect (increase of SW radiation reflected to the absorbing core) during the transport (decrease of SSA) and could explain the opposite results obtained in the model, which simulates an increase of SSA (not shown, Fig. S4) from biomass burning sources to SAO.

\subsubsection{SW heating rate}

Figure 10 indicates the SW heating rates only due to BBA for two transects defined at latitudes of 8 and $15^{\circ} \mathrm{S}$, similar to Fig. 8. The effect of BBA is isolated by subtracting the heating rates in the simulations without BBA from those with BBA. Significant additional SW heating is simulated over the continent and between 2 and $4 \mathrm{~km}$ over the SAO due to the presence of absorbing smoke. Over the continent, the additional heating is about $\sim 1 \mathrm{~K}$ by day with maxima near $\sim 1.5 \mathrm{~K}$ by day for altitude of $\sim 4000 \mathrm{~m}$ at $8^{\circ} \mathrm{S}$. The simulated heating is approximately $1 \mathrm{Kday}^{-1}$ near the coast, decreasing to $0.5 \mathrm{~K} \mathrm{day}^{-1}$ during transport. For both transects, SW heating occurs mainly between 2 and $4 \mathrm{~km}$ over the SAO. At $15^{\circ} \mathrm{S}$, the $\mathrm{SW}$ heating is less pronounced than at $8^{\circ} \mathrm{S}$, in agreement with the difference in the extinction profiles (see Fig. 7). The SW heating due to BBA absorption is clearly visible only above the MBL and there is no clear additional SW heating within it.

Such values of SW heating due to smoke appear to fall well within the range of values reported by different modeling studies by Tummon et al. (2010), Gordon et al. (2018), Adebiyi et al. (2015) or Wilcox (2010), who reported, respectively, additional SW heating due to smoke of 1 (JJAS period), 0.34 (5 days of simulations), 1.2 (for fine AOD > 0.2) and $1.5 \mathrm{~K}$ by day. In addition, Keil and Haywood (2003) estimated a SW heating rate of $1.8 \mathrm{~K} \mathrm{day}^{-1}$ near the coast using

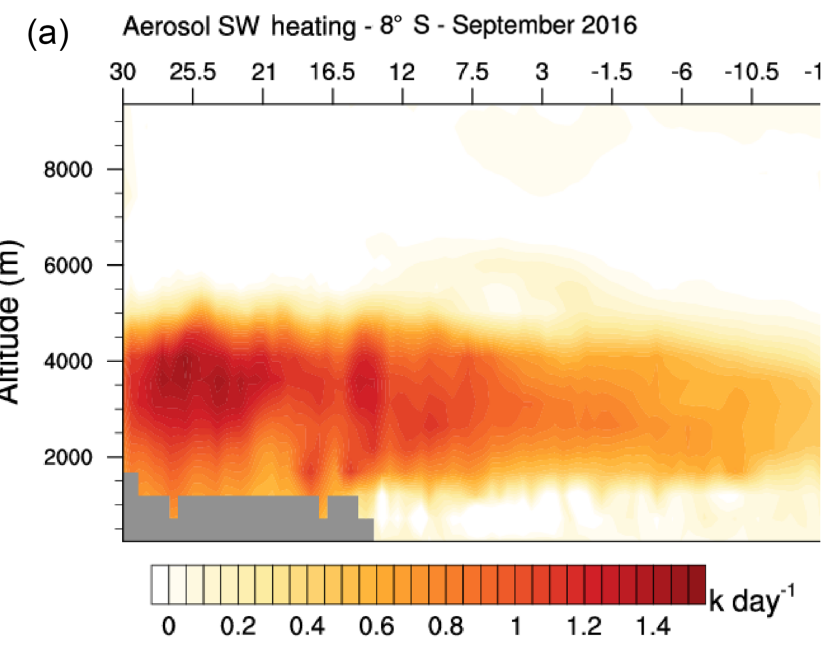

(b) Aerosol SW heating - $15^{\circ} \mathrm{S}$ - September 2016

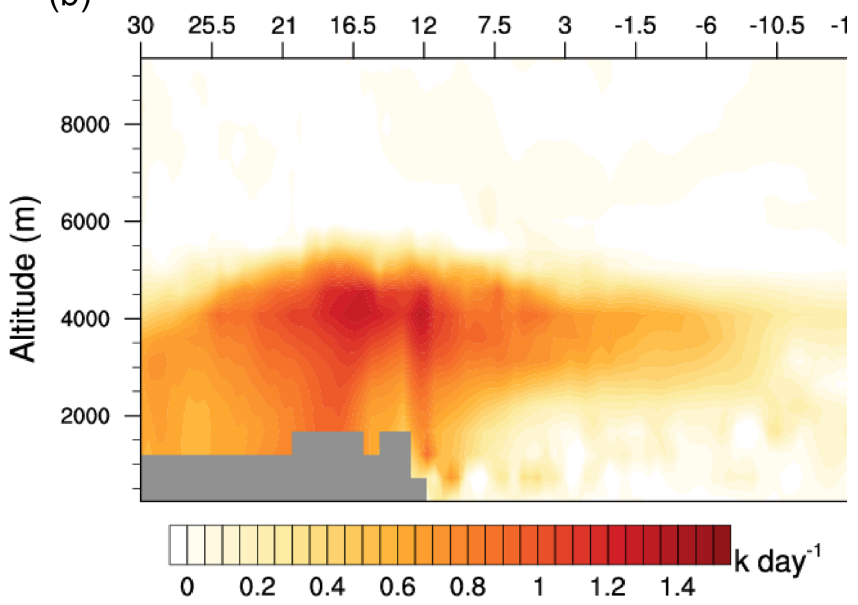

Figure 10. Monthly mean (September 2016) aerosol SW heating rate vertical profiles simulated by the ALADIN-Climate model for two transects at latitudes of 8 (a) and $15^{\circ} \mathrm{S}(\mathbf{b})$. Longitudes are between $30^{\circ} \mathrm{E}$ and $11.5^{\circ} \mathrm{W}$.

a radiative transfer model and observations during SAFARI2000. The temperature change (estimated through two parallel simulations including smoke or not) due to BBA is about $+0.5-0.8 \mathrm{~K}$ between 2 and $4 \mathrm{~km}$ (Fig. S5 in the Supplement) in good agreement with the value $(+0.5 \mathrm{~K})$ of Sakaeda et al. (2011) or more recently proposed by Gordon et al. (2018). It should be noted that there is a large impact of less absorbing BBA (mostly present at the end of the biomass burning season; Eck et al., 2013) on SW heating rate as reported in Table 3. Results obtained with the SMK_SSA simulations indicate a change from 1.15 (SMK) to $0.58 \mathrm{~K} \mathrm{day}^{-1}$ (SMK_SSA) over box_S.

ORACLES SW heating rates retrieved from the SSFR retrievals of SSA and ASY (see the "SW heating rate estimates" section) in conjunction with HSRL2 extinction profiles (the "aerosol extinction profiles" section) are also used to assess our simulations. Figure 11 indicates the instanta- 
Table 3. Monthly mean (September 2016) all-sky direct radiative effect at TOA and bottom of the atmosphere $\left(\mathrm{BOA}\right.$; W $\mathrm{m}^{-2}$ ) and $\mathrm{SW}$ heating rate at $3 \mathrm{~km}\left(\mathrm{~K} \mathrm{day}^{-1}\right)$ for the two boxes (box_S and box_O), obtained from the SMK and SMK_SSA simulations.

\begin{tabular}{lrr|rr|rr}
\hline & \multicolumn{2}{c}{ DRE_BOA } & \multicolumn{2}{c|}{ DRE_TOA } & \multicolumn{2}{c}{ SW heating (3 km) } \\
\cline { 2 - 7 } & Box_S & Box_O & Box_S & Box_O & Box_S & Box_O \\
\hline ALD_SMK & -38.93 & -15.73 & -3.92 & +4.22 & 1.15 & 0.75 \\
ALD_SMK_SSA & -24.81 & -8.17 & -7.37 & -0.54 & 0.58 & 0.30 \\
\hline
\end{tabular}

neous (12:00 UTC) SW heating (only due to aerosols) vertical profiles obtained for 20 September from SSFR and ALADIN-Climate. Two ALADIN-Climate heating profiles indicate clear-sky and all-sky conditions. Figure 11 indicates that the location of the additional SW heating due to BBA is well represented by the model, with a notable increase between 3 and $4 \mathrm{~km}$, in agreement with the SSFR retrievals. SW heating between 2 and $2.5 \mathrm{~K} \mathrm{day}^{-1}$ is simulated at these altitudes, with the highest values obtained under all-sky conditions (dashed black lines). However, significant underestimates are observed within the smoke layer, where SSFR observations indicate SW heating of about $\sim 3$ to $3.5 \mathrm{~K} \mathrm{day}^{-1}$. As the Sc COD is found to be consistent between simulations and the SSFR cloud retrievals (COD $\sim 9$ ), we hypothesize that the difference in SW heating is due to local underestimates of aerosol extinction as well as of BBA absorption in the model. A second aspect concerns the large underestimate of SW heating around $\sim 1.5 \mathrm{~km}$ in the ALADIN-Climate simulation. Indeed, the local maxima of $\sim 2.5 \mathrm{~K} \mathrm{day}^{-1}$ obtained from SSFR observations are totally absent in the model but can be traced back to another layer detected by HSRL.

\subsection{Impact of the RH transported within the smoke plume on optical properties}

As mentioned previously, a specific simulation (SMK_SN) that includes the method of spectral nudging (Radu et al., 2008) was also performed. The nudging is applied to wind vorticity and divergence, surface pressure, temperature and specific humidity, using a constant rate above $700 \mathrm{hPa}$, a relaxation zone between 700 and $850 \mathrm{hPa}$, while the levels below $850 \mathrm{hPa}$ are free. This simulation was motivated by different studies (Haywood et al., 2003; Adebiyi et al., 2015) that indicated a correlation between BBA and specific humidity. In these studies, biomass burning plumes are associated with specific humidities greater than $2 \mathrm{~g} \mathrm{~kg}^{-1}$, while outside the smoke plumes the values are less than $1 \mathrm{~g} \mathrm{~kg}^{-1}$. To date, few regional climate modeling studies have investigated the potential role of the relative humidity on smoke optical properties within this specific atmospheric layer, that could, in turn, impact the DRE exerted by BBA. This ALADINClimate simulation (SMK_SN) addresses this specific point.

Figure $4 \mathrm{~b}$, showing the daily mean ACAOD (averaged over box_O) from MODIS-DB along with the simulations

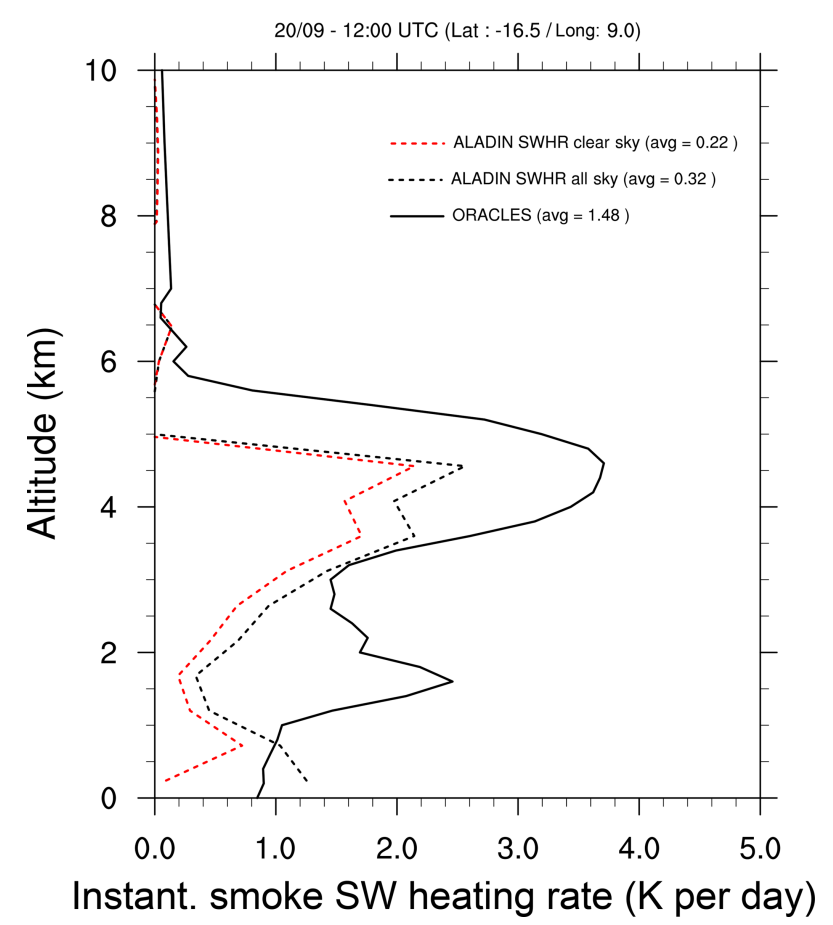

Figure 11. Instantaneous SW heating rate (12:00 UTC) only due to smoke aerosols, obtained from ORACLES aircraft data and simulated by the ALADIN-Climate model in clear-sky (dashed red lines) and all-sky (dashed blue lines) conditions.

through comparing the ACAOD with and without the nudging, indicates an impact. For SMK_SN, the negative bias is reduced compared to MODIS-DB and is equal to -0.02 (bias of -0.06 for the SMK run). The maxima in ACAOD observed between 19 and 25 September are better reproduced in the SMK_SN simulation, consistent with a slightly improved temporal correlation (0.42).

In addition to the satellite observations, we also used HSRL-2 vertical profiles of extinction (already presented in Fig. 8) to investigate the impact of RH on BBA optical properties. Figure 12 shows, for 24 September only, the vertical profiles of RH by MERRA-2 and ALADIN-Climate (SMK and SMK_SN simulations), as well as aerosol extinction (at $550 \mathrm{~nm}$ ) from HSRL-2 and the model (SMK and SMK_SN). A significant improvement is evident in the SMK_SN RH vertical profiles, reducing the bias with MERRA-2, espe- 
cially at 09:00 and 12:00 UTC. For each case, Fig. 12 indicates that RH is better represented in SMK_SN especially at altitudes where the transport of smoke occurs, i.e., between 2000 and $5000 \mathrm{~m}$ (Fig. 7).

These changes in RH profiles in SMK_SN run impact the BBA optical properties for the different cases, notably by increasing extinction within the smoke plume, and a remarkable agreement in extinction is observed between HSRL-2 and the SMK_SN simulation. As an example, at 09:00 UTC, the improvement of the simulated $\mathrm{RH}$ between 3500 and $6000 \mathrm{~m}$ in SMK_SN significantly reduces the bias in the simulated extinction at those altitudes. At $4500 \mathrm{~m}$, the simulated extinction is very consistent with HSRL-2, with maxima around $\sim 0.2 \mathrm{~km}^{-1}$. Similar conclusions are also observed for the other cases presented in Fig. 12. At 11:00 UTC, important improvements are found for altitudes between 2000 and $5000 \mathrm{~m}$ in the SMK_SN simulation compared to SMK. At this time, a negative bias persists between 2000 and $3500 \mathrm{~m}$, marked by a bias in RH even in the nudged simulation. These results are consistent with the study of Adebiyi et al. (2015), who used CALIPSO smoke extinction profiles to show that the largest extinction coefficients co-occur with high RH $(\sim 80 \%)$ at the top of the BBA layer. As discussed recently in Kar et al. (2018), this increase could be due to enhancement of the size of aged smoke during the transport over the SAO.

A second important aspect of these results concerns the possible overestimates of the increase of extinction with $\mathrm{RH}$ as parameterized in the present version of ALADIN-Climate. As indicated for both cases, excellent agreement is generally observed in the extinction profiles even if some slight negative bias in RH remains. This can be clearly detected at $4500 \mathrm{~m}$ (09:00 UTC) or $4000 \mathrm{~m}$ (11:00 UTC). At 12:00 UTC, and for altitudes between 1000 and $2000 \mathrm{~m}$, RH simulated in SMK_SN is consistent with MERRA-2 data, while the simulated extinction is overestimated.

These original results, using for the first time coincident in situ observations and nudged simulations (allowing the capture of the elevated humidity transported within smoke plume) of aerosol extinction within BBA plume, clearly indicate the significant impact of RH on BBA optical properties. This underlines the importance of including in models the fire processes related to the presence of humidity in the smoke plume over the SAO. A second important aspect concerns the presence of possible errors in the actual parameterization used in ALADIN-Climate to calculate the evolution of BBA extinction with RH. In that sense, nudged simulations, associated with in situ data obtained during ORACLES, would certainly provide a unique opportunity to test and constrain the hydrophilic properties of BBA over the SAO. Future work will extend significantly the number of cases studied to test the robustness of these first results.

\section{Direct radiative forcing and impact of $\mathrm{BBA}$}

\subsection{DRE exerted at TOA}

The monthly mean DRE exerted at TOA (in the visible spectral range) is indicated in Fig. 13 in clear-sky (left) and allsky (right) conditions. The ALADIN-Climate estimates do not include possible SST adjustments due to $\mathrm{BBA}$ radiative effects, even if this could be important over the SAO (Sakaeda et al., 2011). Figure 13 indicates an important regional gradient in the sign of DRE over the domain in all-sky conditions, with a rather negative forcing over the continent (net cooling) and positive (net heating) over the SAO. Over the continent, the mean DRE is found to be mostly negative $\left(\sim-5 /-15 \mathrm{~W} \mathrm{~m}^{-2}\right)$ over Angola, with local maxima up to $-20 \mathrm{~W} \mathrm{~m}^{-2}$. An interesting result concerns the presence of significant positive forcings along the coast from Gabon to Namibia, with values of $\sim+10$ to $+20 \mathrm{~W} \mathrm{~m}^{-2}$. Such significant positive forcing at TOA is correlated with both the presence of Sc clouds along the coast of Angola, the Democratic Republic of the Congo and Gabon (see Fig. S6 in the Supplement) and the high surface albedo over Namibia (Fig. 1).

On the contrary, over the SAO, DRE exerted at TOA is found to be mainly positive in all-sky conditions, in agreement with a large body of literature focused on this region (Meyer et al., 2013; Feng and Christopher, 2015; De Graaf et al., 2012, 2014; Zuidema et al., 2016). The impact of the presence of Sc clouds on the sign of DRE at TOA is clearly shown when comparing the ALADIN-Climate simulations in clear-sky and all-sky conditions. The large cooling effect at TOA is replaced by a significant heating over a large part of SAO. However, and when averaged over the same region $\left(20^{\circ} \mathrm{S}-10^{\circ} \mathrm{N}\right.$ and $\left.10^{\circ} \mathrm{W}-20^{\circ} \mathrm{E}\right)$ as defined in Feng and Christopher (2015), an important underestimate is detected compared to satellite observations. Indeed, the instantaneous (at satellite overpass time) monthly averaged DRE is found to be about $+6 \mathrm{~W} \mathrm{~m}^{-2}$ in ALADIN-Climate and $\sim+35 \mathrm{~W} \mathrm{~m}^{-2}$ in the study of Feng and Christopher (2015). A better agreement is obtained with Oikawa et al. (2013), who reported an annual mean of $+3 \mathrm{~W} \mathrm{~m}^{-2}$ over southern Africa using CALIPSO and GCM simulation. More recently, Gordon et al. (2018) indicate a regional DRE of $+11 \mathrm{~W} \mathrm{~m}^{-2}$ at TOA close to the one obtained in this study but for 5 smoky days. We suspect the underestimate of LCF (Fig. 2b) to be mostly responsible for this large difference with the Feng and Christopher (2015) estimates. Interestingly, comparisons with the climatological estimates based on MACC NRT data for the period 2010-2015 (Fig. S7 of the Supplement) indicate important differences. Figure S7 indicates that the positive DRE simulated by ALADIN-Climate is absent in the MACC NRT data, except locally over the continent.

Finally, the SMK_SSA simulations indicate a significant changes in the monthly mean (September 2016) DRE exerted at TOA, passing from a positive $\left(+4.2 \mathrm{~W} \mathrm{~m}^{-2}\right)$ to negative $\left(-0.54 \mathrm{~W} \mathrm{~m}^{-2}\right)$ DRE (Fig. 13 and Table 3 ) over box_O. 
(a)

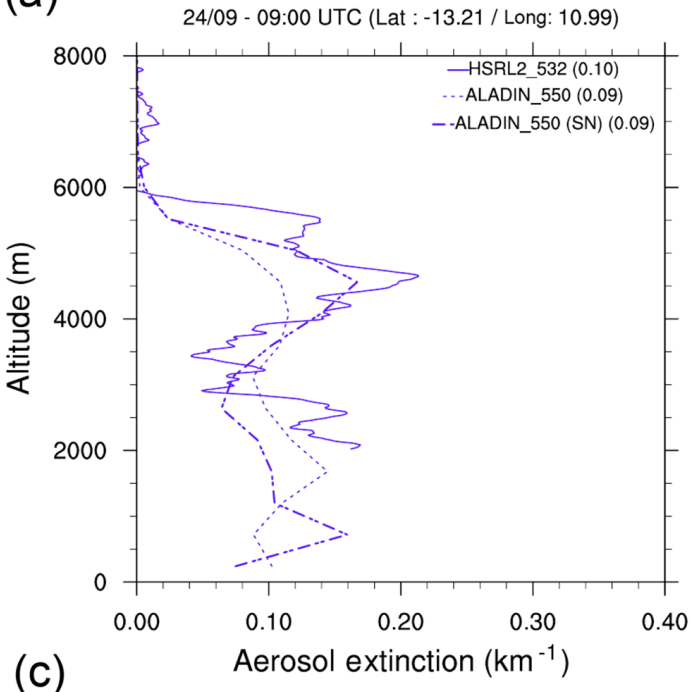

(c)

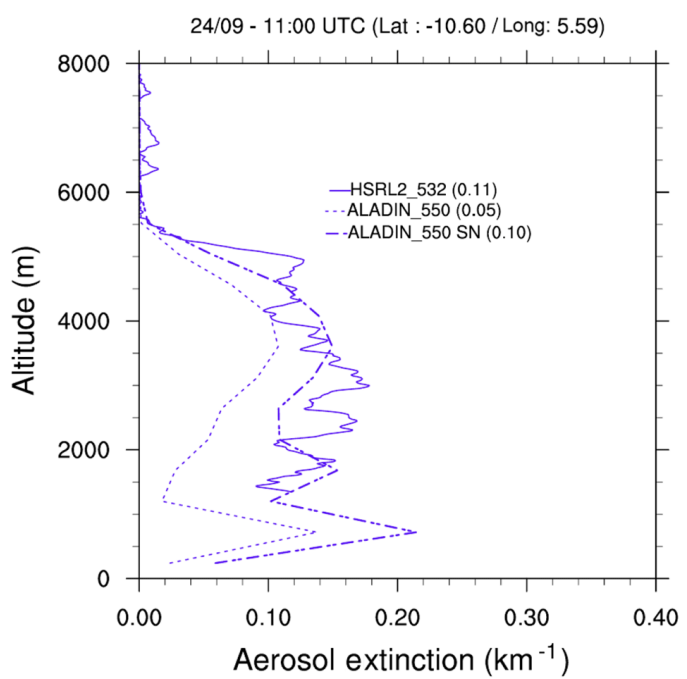

(e)

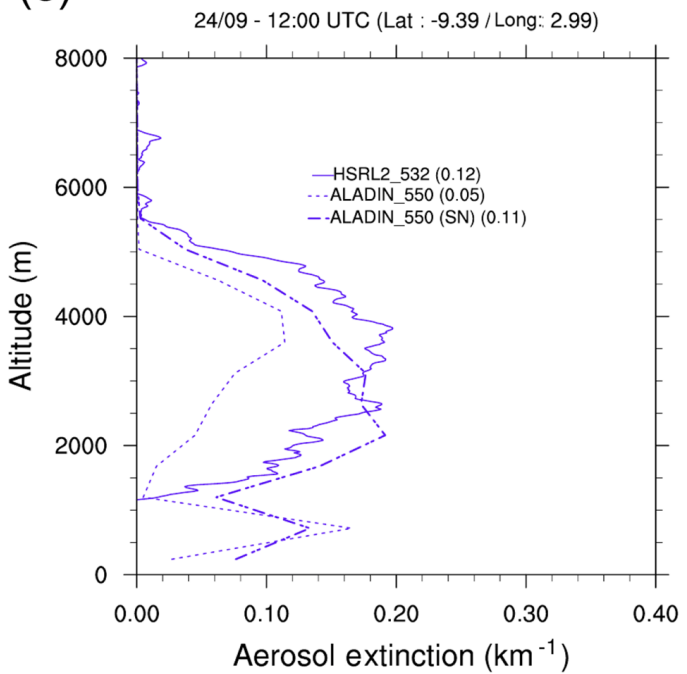

(b)

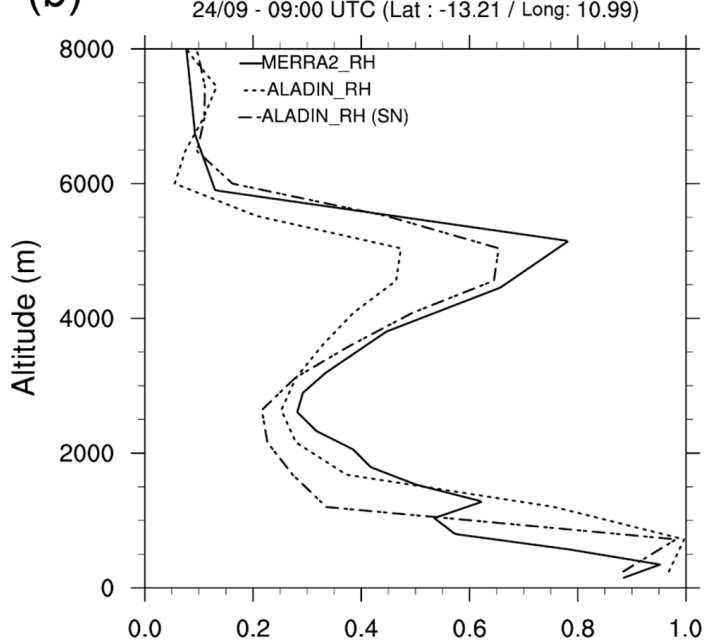

(d)

Relative humidity

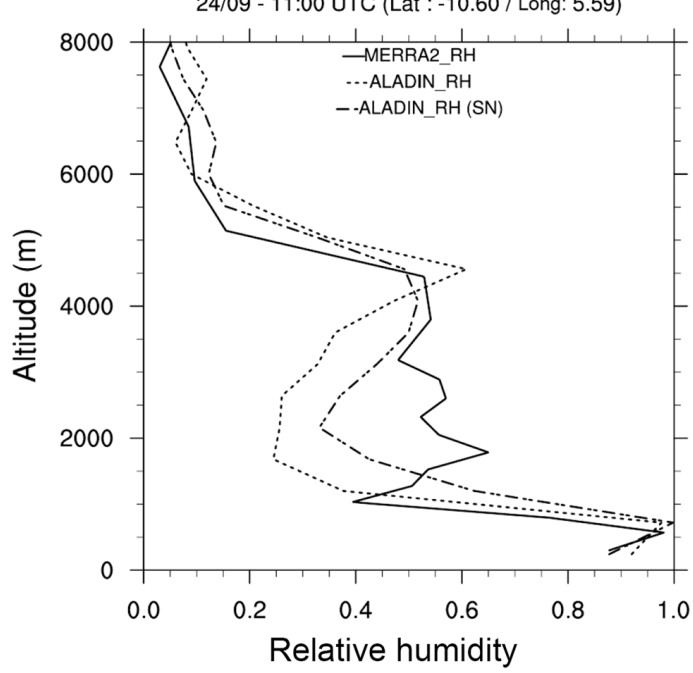

(f)

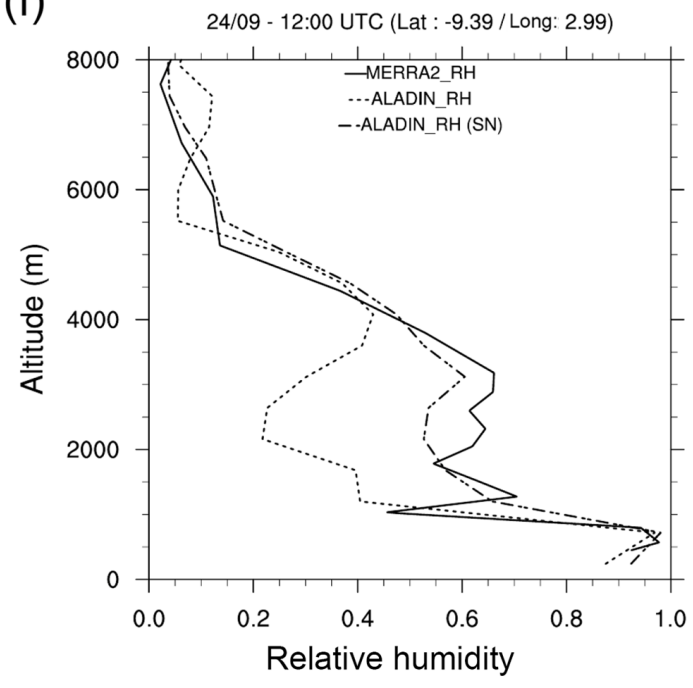

Figure 12. Vertical profiles of aerosol extinction coefficient (at $550 \mathrm{~nm}$ ) obtained from ALADIN-Climate for the SMK and SMK_SN simulations and derived from the HSRL-2 instrument for 24 September, associated with the vertical mean (a, c, e). Also reported is the RH obtained from the same simulations and MERRA-2 data $(\mathbf{b}, \mathbf{d}, \mathbf{f})$. 
ALADIN-Climate monthly mean DRF (SW) at TOA - September 2016

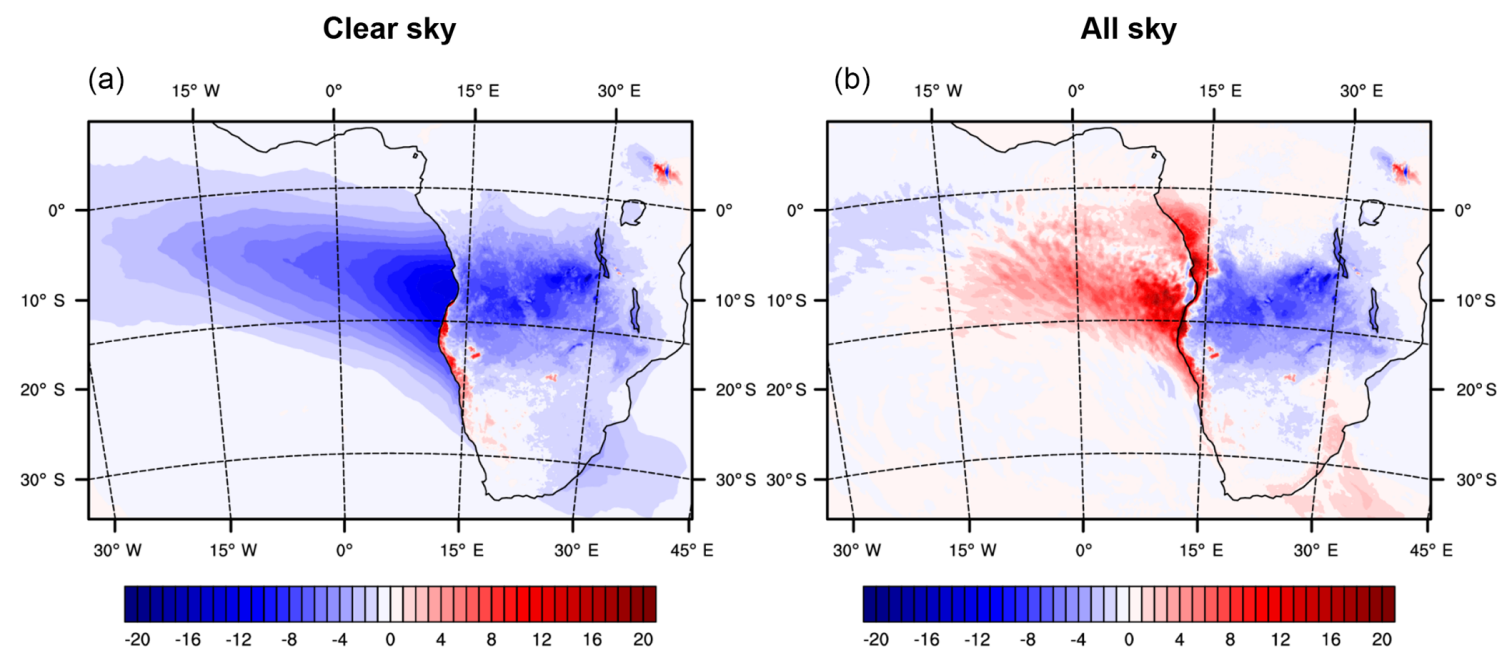

All sky-SSA_0.92

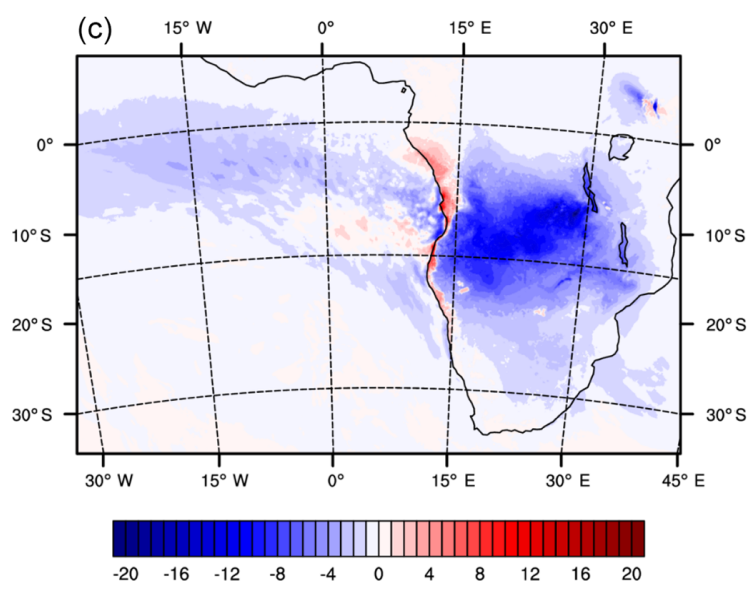

Figure 13. Monthly mean SW DRE $\left(\mathrm{W} \mathrm{m}^{-2}\right)$ exerted by smoke particles at TOA for the September 2016 period in clear-sky (a) and allsky (b) conditions for the SMK simulation and for the (c) SMK_SSA run.

This means that the positive DRE at TOA could be weaker at the end of BBA season (late October). Figure 13 indicates a more intense negative DRE at TOA over smoke sources due to more scattering BBA, and over box_S, the monthly mean value (Table 3 ) is increasing from $-3.9 \mathrm{~W} \mathrm{~m}^{-2}$ (SMK) to $-7.3 \mathrm{~W} \mathrm{~m}^{-2}$ (SMK_SSA). In addition, a weaker positive DRE is observed at TOA along the southern African coast and Gabon due to more scattering smoke.

\subsection{Impact on the continental surface energy budget and dynamics}

The potential impact of BBA on the "continental climate" has been investigated by using the differences between the CTL and SMK simulations. Figure 14 shows the monthly mean difference (September 2016) of the following variables; surface net SW radiation (Fig. 14a), $2 \mathrm{~m}$ temperature
$\left(T_{2 \mathrm{~m}}\right.$; Fig. 14b), sensible heat fluxes (SHFs; Fig. 14c) and the PBL height (Fig. 14d). The potential effect of BBA on the continental precipitation is not studied, as little or no precipitation occurs south of approximately $8^{\circ} \mathrm{S}$ during the austral winter season.

Smoke aerosols are responsible for an important dimming of about -30 to $-50 \mathrm{~W} \mathrm{~m}^{-2}$ (monthly mean) over the continent and -10 to $-40 \mathrm{~W} \mathrm{~m}^{-2}$ over the SAO during September 2016, with the highest impact logically located over smoke sources. Such estimates are consistent with those reported by Sakaeda et al. (2011) or Tummon et al. (2010). This impact of BBA results in an important decrease in the $T_{2 \mathrm{~m}}$ over the Democratic Republic of the Congo, Angola and Zambia, as well as certain regions of southern Africa. The impact is approximately $\sim-1$ to $-3^{\circ} \mathrm{C}$ over the continent, in good agreement with the values reported by Sakaeda et al. (2011). When averaged over box_S $\left(5-15^{\circ} \mathrm{S}, 15-25^{\circ} \mathrm{E}\right)$, 

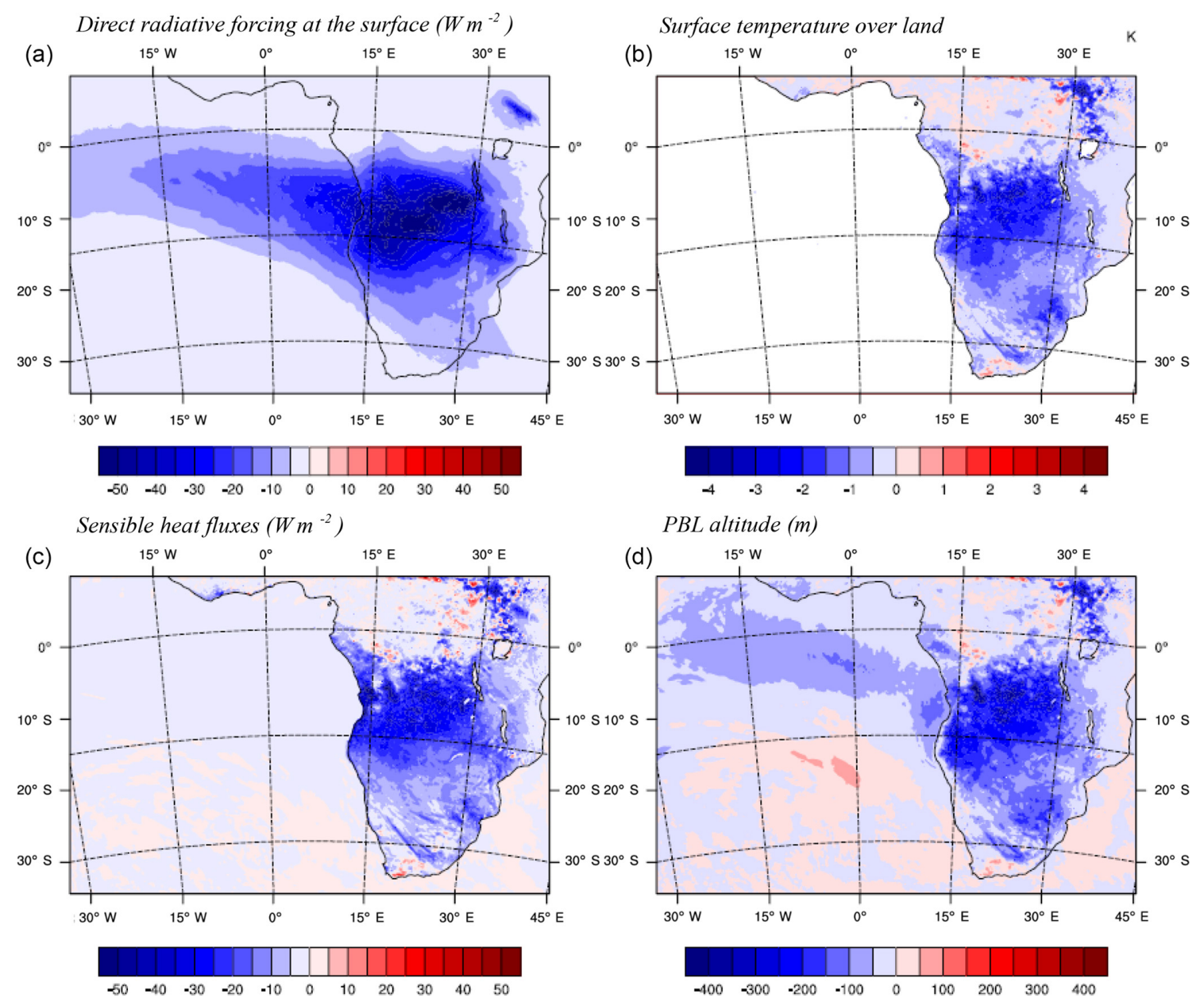

Figure 14. Differences between the CTL and SMK ALADIN-Climate runs in the monthly mean (September 2016) SW surface radiation (a), $2 \mathrm{~m}$ continental temperature (b), sensible heat fluxes (c) and PBL height (d).

the impact of BBA on $T_{2} \mathrm{~m}$ is about $-1.7^{\circ} \mathrm{C}$ during September 2016 (Fig. 15a). The daily mean impact of BBA remains constant during this period, except for the end of September, when the effect is negligible. For 26 to 31 September, we hypothesize that compensations should occur, the "dynamical" effect of BBA being more important than the "dimming" effect. As mentioned previously and contrary to Sakaeda et al. (2011), the impact of BBA on SST is not quantified, as the ALADIN-Climate simulations have been performed with prescribed SST. Finally, it should be noted that the change of the surface temperature per unit of AOD (averaged for all the period of simulation) is about $\sim-2.5^{\circ} \mathrm{C}$. This value is found to be higher than the one $\left(-1.5^{\circ} \mathrm{C}\right.$ per unit $\left.\mathrm{AOD}\right) \mathrm{re}-$ ported by Zhang et al. (2016) for an extreme biomass burning event occurring over central Canada during June 2015. The difference could be due to the absorbing properties of BBA, which are more pronounced in the present study compared to Zhang et al. (2016), with SSA of $0.94(550 \mathrm{~nm})$. This could favor higher dimming effect and related impact on the surface temperature over the Angola region.
In parallel with the changes in surface temperature, the SHFs (Fig. 14c) significantly decrease, indicating weaker fluxes, over almost the entire subcontinent, with maxima in the main biomass burning sources. The decrease is about -20 to $-30 \mathrm{~W} \mathrm{~m}^{-2}$ over the continent, with a mean value of $-25 \mathrm{~W} \mathrm{~m}^{-2}$ when averaged over box_S (Fig. 15b). The impact of smoke is important throughout the whole time period, with SHFs changing from a (monthly mean) value of 85 to $60 \mathrm{~W} \mathrm{~m}^{-2}$ for the CTL and SMK runs, respectively. This is consistent with the findings of Sakaeda et al. (2011) or Tummon et al. (2010). Indeed, the latter report a decrease over almost the entire subcontinent, with a maximum (decrease of $\sim 50 \%$ ) in the main smoke region. As a result of the significant decrease in $T_{2} \mathrm{~m}$ and SHFs over much of the subcontinent, the PBL height (defined as the top of the PBL) also decreases in the SMK run. This decrease is significant over much of the subcontinent, in accordance with the results of Tummon et al. (2010), with regional maxima up to $\sim-400 \mathrm{~m}$ (Fig. 14, bottom right). The lowest changes are observed along the west coast between 10 and $15^{\circ} \mathrm{S}$ and 

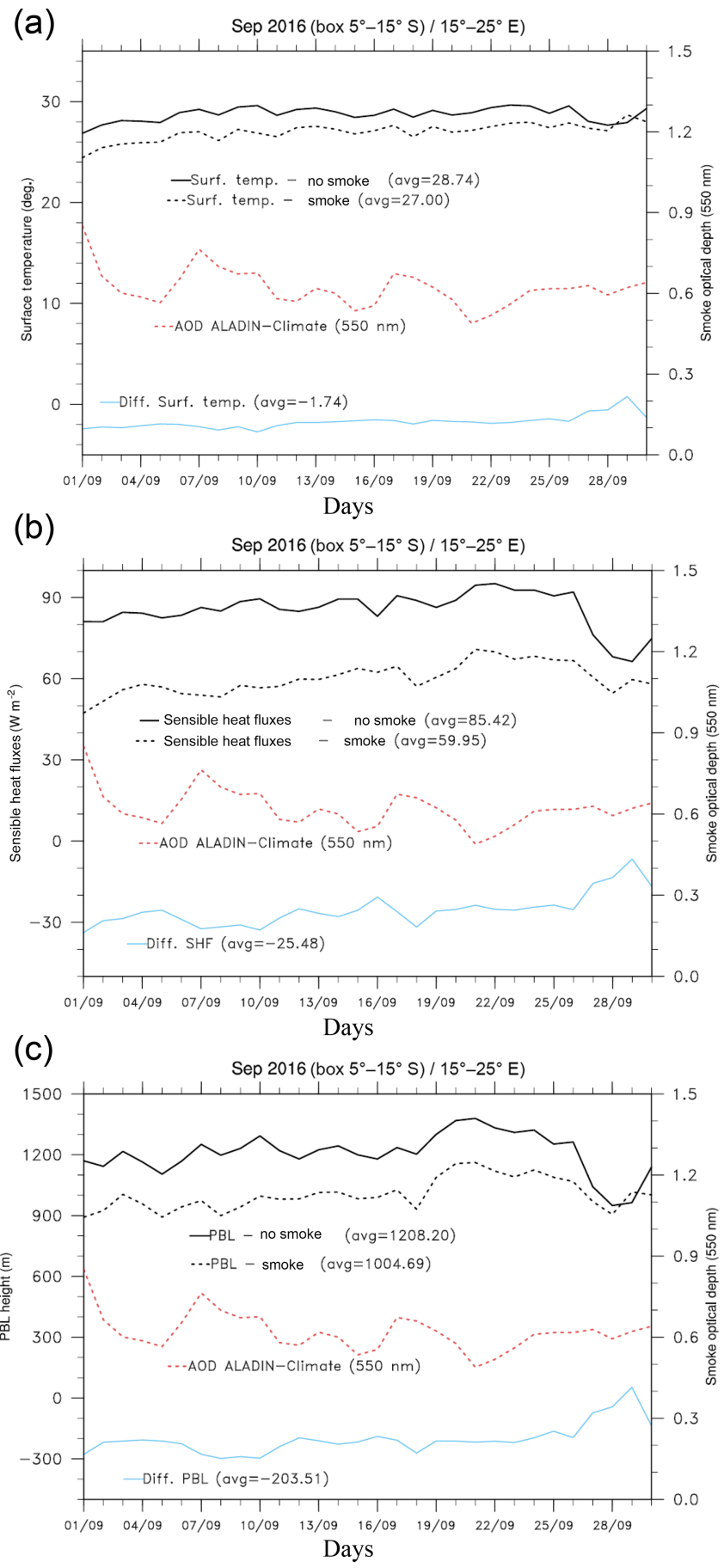

Figure 15. Daily mean surface temperature, sensible heat fluxes and PBL height obtained from the CTL (black lines) and SMK (dashed black lines) ALADIN-Climate simulations for September 2016. The AOD (dashed red lines) and the difference between the two simulations (CTL and SMK) for each variable are also reported (blue lines). small regions of increased PBL height occur over southern Namibia and northern Angola consistent with increases in the surface temperature. When averaged over the continent (box_S), the decrease in the PBL height is also significant, changing from $\sim 1200$ to $\sim 1000 \mathrm{~m}$ (averaged monthly) for the CTL and SMK simulations (Fig. 15c), respectively. The decrease is nearly constant during September 2016, except for 25 to 30 September (decrease), and not necessarily correlated with AOD. The difference in the PBL height can reach a maximum decrease of $300 \mathrm{~m}$ (Fig. 15c). In parallel, the impact of BBA on the near-surface $(10 \mathrm{~m})$ wind speed (not shown) indicates a general decrease (of about $-0.5 \mathrm{~m} \mathrm{~s}^{-1}$ ) over most of the continent. Over the ocean, the impact is more complex with the presence of a contrast, characterized by an increase (decrease) of the surface wind around 15$30^{\circ} \mathrm{S}, 0-10^{\circ} \mathrm{W}$ (latitudes higher than $15^{\circ} \mathrm{S}$ ).

Finally, the comparisons with the SMK_SSA simulations (not shown, Fig. S8) indicate a decrease of the surface radiative forcing both over continent and ocean. As reported in Table 3, the monthly mean DRE at BOA is about -39 and $-25 \mathrm{~W} \mathrm{~m}^{-2}$ over box_S for the SMK and SMK_SSA simulations, respectively (similar results are obtained over the SAO). This is due to the decrease of SW radiation absorbed by smoke in the SMK_SSA simulation, increasing the SW radiation reaching the surface. This could be also due, to a lesser extent, to changes in the aerosol loading due to modifications of the dynamics and precipitations between the two simulations. This induces a less pronounced impact of BBA on the surface temperature and sensible heat fluxes in SMK_SSA. The increase of SW surface radiation, associated with lower absorption by BBA, decreases the impact on the PBL development (Fig. S8). As mentioned previously, these results suggest that the impact of BBA on the surface fluxes and dynamics is certainly weaker at the end of the biomass burning season.

\section{Conclusions}

The transport, vertical structure, SW radiative heating, SW direct radiative effect and climatic impact exerted by absorbing BBA in the SAO have been estimated for September 2016 using the ALADIN-Climate model in the context of the ORACLES and LASIC projects. The model is able to represent LWP and COD well, although with a large underestimate in LCF. The simulated BBA AOD is consistent over the continent $(\sim 0.7$ at $550 \mathrm{~nm})$ compared to MERRA-2 or MODIS data and also locally against AERONET data. We have also used new recent retrievals of ACAOD (OMI or MODIS) to demonstrate the ability of the model to reproduce reasonable values of smoke concentrations above Sc clouds during the transport over the SAO.

The simulations indicate the transport of BBA over the SAO mainly occurs between 2 and $4 \mathrm{~km}$, consistent with aircraft lidar observations. There is some indication that the 
entrainment of BBA in the MBL could be underestimated by the model, contrary to the recent literature (Zuidema et al., 2018). This possible bias could lead to underestimate the BBA indirect forcing in this ALADIN-Climate configuration. In parallel, the absorbing properties (SSA) of BBA are consistent over biomass burning sources compared to AERONET but significantly higher when compared to Ascension Island (LASIC) surface observations. The significant difference could be due to the absence of internal mixing treatment in the model, a lack of representation of the longrange aging processes and/or the absence of mixing of BBA in the MBL. In addition, the important SW absorption by BBA produces an additional SW heating of $\sim 1 \mathrm{Kday}^{-1}$.

The ALADIN-Climate simulations reveal a significant regional gradient in the sign of the SW DRE at TOA (allsky conditions and fixed SST conditions), with mostly negative (continent) and positive (SAO) forcing, mainly due to changes in the underlying albedo associated with highly absorbing BBA. Over the continent, an intense monthly mean positive forcing $\left(+10 /+15 \mathrm{~W} \mathrm{~m}^{-2}\right)$ is simulated over Gabon, part of the Democratic Republic of the Congo and Angola, mainly due to the presence of low Sc clouds. Over the SAO, a DRE of $+6 \mathrm{~W} \mathrm{~m}^{-2}\left(20^{\circ} \mathrm{S}-10^{\circ} \mathrm{N}\right.$ and $\left.10^{\circ} \mathrm{W}-20^{\circ} \mathrm{E}\right)$ is simulated at TOA during the entire ORACLES-1 period.

One of the main original results concerns the use of coincident in situ observations and nudged simulations (allowing to capture the elevated humidity transported within the smoke plume) of aerosol extinction within the BBA plume. Results highlight the significant effect of enhanced moisture on BBA extinction that considerably reduces the negative bias (in the simulated extinction) in the nudged simulation (SMK_SN) with ORACLES-1 data, compared to the SMK (no nudging) run. A second important aspect concerns the possible errors in the actual parameterization used to estimate the changes in BBA extinction with $\mathrm{RH}$ in the model. Indeed, our results indicate a possible overestimate of the increase in smoke extinction due to RH when compared to ORACLES-1 observations. Nudged simulations, associated with in situ observations, would certainly provide a unique dataset to test and constrain the hygroscopic properties of BBA over the SAO. All of these points have possible implications for DRE considerations and future works will extend significantly the number of cases studied to test the robustness of the results.

For September 2016, the important negative surface dimming due to BBA (around -5 to $-15 \mathrm{~W} \mathrm{~m}^{-2}$ ) over the subcontinent significantly modifies the surface energy budget over much of southern Africa. Indeed, the decrease in the net surface SW radiation is compensated by a decrease in sensible heat fluxes $\left(-25 \mathrm{~W} \mathrm{~m}^{-2}\right.$, monthly mean) and surface land temperature $\left(-1.5^{\circ} \mathrm{C}\right)$ over Angola, Zambia and the Democratic Republic of the Congo, notably. The association of the surface cooling and the lower tropospheric heating tends to decrease the continental PBL height over the continent by about $\sim 200 \mathrm{~m}$.
Finally, the indirect radiative effect exerted by BBA remains to be investigated with the ALADIN-Climate model using ORACLES/CLARIFY/AEROCLO-sA data in a manner similar to that presented here for DRE considerations. Once evaluated for all forcings over this region, long-term simulations (ERA-INT period) will be done to assess the possible feedbacks of BBA on Sc properties and the regional radiative budget at a climatic scale.

Data availability. MODIS data are available from the NASA Level 1 and Atmosphere Archive and Distribution System Distributed Active Archive Center at https://ladsweb.modaps.eosdis.nasa.gov/ (last access: 2018). MODIS above-cloud data products are available from the authors upon request. MISR data are available from the NASA Atmospheric Sciences Data Center at https://eosweb.larc. nasa.gov/ (last access: 2018).

Supplement. The supplement related to this article is available online at: https://doi.org/10.5194/acp-19-4963-2019-supplement.

Author contributions. PN and MM designed the ALADIN-Climate configuration, and MM performed the simulations. RR, DSM, PN developed the ALADIN-Climate model. AMS, MS, KM, HJ, OT and $\mathrm{CH}$ have participated in providing the different aerosol satellite products. PZ provided in situ LASIC (Ascension Island) observations; SS and SC provided data from the SSFR instrument. SB and RF participated in providing the HSRL-2 data. JR, RW, PS, PF and all co-authors have participated in the analysis of all observations and simulations. MM finalized the manuscript with contributions from all co-authors.

Competing interests. The authors declare that they have no conflict of interest.

Special issue statement. This article is part of the special issue "New observations and related modelling studies of the aerosolcloud-climate system in the Southeast Atlantic and southern Africa regions (ACP/AMT inter-journal SI)". It is not associated with a conference.

Acknowledgements. This work has been conducted in the frame of the ORACLES investigation under the National Aeronautics and Space Administration's Earth Venture program. The LASIC extinction and SSA values are available through https://doi.org/10.5439/1369240, obtained from the Atmospheric Radiation Measurement (ARM) User Facility, a US Department of Energy (DOE) Office of Science user facility managed by the Office of Biological and Environmental Research. Paquita Zuidema acknowledges support from DOE ASR grant DE-SC0018272. AERONET data are available from https://aeronet.gsfc.nasa.gov (last access: November 2018). 
Marc Mallet, Pierre Nabat and Paola Formenti acknowledge the AErosols, Radiation and CLOuds in southern Africa (AEROCLOsA) project, supported by the French National Research Agency under grant agreement no. ANR-15-CE01-0014-01, the French national program LEFE/INSU, the Programme national de Télédetection Spatiale (PNTS; http://www.insu.cnrs.fr/pnts (last access: 2018), grant nos. PNTS-2016-02 and PNTS-2016-14, the French National Agency for Space Studies (CNES), the Centre National de la Recherche Scientifique (CNRS), the South African National Research Foundation (NRF) under grant UID 105958 and the European Union's Seventh Framework Programme (FP7/2014-2018) under EUFAR2 contract no. 312609. We thank the CNRM climate model development team.

Review statement. This paper was edited by Joshua Schwarz and reviewed by Jeffrey Reid and one anonymous referee.

\section{References}

Abel, S. J., Haywood, J. M., Highwood, E. J., Li, J., and Buseck, P. R.: Evolution of biomass burning aerosol properties from an agricultural fire in southern Africa, Geophys. Res. Lett., 30, 1783, https://doi.org/10.1029/2002GL017342, 2003.

Adebiyi, A. and Zuidema, P.: The role of the southern African easterly jet in modifying the southeast Alantic aerosol and cloud environments, Q. J. Roy. Meteor. Soc., 142, 1574-1589 https://doi.org/10.1002/qj.2765, 2016.

Adebiyi, A. A., Zuidema, P., and Abel, S. J.: The convolution of dynamics and moisture with the presence of shortwave absorbing aerosols over the southeast Atlantic, J. Climate, 28, 1997-2024, https://doi.org/10.1175/JCLI-D-14-00352.1, 2015.

Bellouin, N., Rae, J., Jones, A., Johnson, C., Haywood, J., and Boucher, O.: Aerosol forcing in the Climate Model Intercomparison Project (CMIP5) simulations by HadGEM2-ES and the role of ammonium nitrate, J. Geophys. Res., 116, D20206, https://doi.org/10.1029/2011JD016074, 2011.

Benas, N., Finkensieper, S., Stengel, M., van Zadelhoff, G.-J., Hanschmann, T., Hollmann, R., and Meirink, J. F.: The MSGSEVIRI-based cloud property data record CLAAS-2, Earth Syst. Sci. Data, 9, 415-434, https://doi.org/10.5194/essd-9-415-2017, 2017.

Benedetti, A., Morcrette, J.-J., Boucher, O., Dethof, A., Engelen, R. J., Fisher, M., Flentjes, H., Huneeus, N., Jones, L., Kaiser, J. W., Kinne, S., Mangold, A., Razinger, M., Simmons, A. J., Suttie, M., and the GEMS-AER team: Aerosol analysis and forecast in the ECMWF Integrated Forecast System: 2. Data assimilation, J. Geophys. Res., 114, D13205, https://doi.org/10.1029/2008JD011115, 2009.

Burton, S. P., Hair, J. W., Kahnert, M., Ferrare, R. A., Hostetler, C. A., Cook, A. L., Harper, D. B., Berkoff, T. A., Seaman, S. T., Collins, J. E., Fenn, M. A., and Rogers, R. R.: Observations of the spectral dependence of linear particle depolarization ratio of aerosols using NASA Langley airborne High Spectral Resolution Lidar, Atmos. Chem. Phys., 15, 13453-13473, https://doi.org/10.5194/acp-15-13453-2015, 2015.

Burton, S. P., Hostetler, C., Cook, A., Hair, J., Seaman, S. T., Scola, S. J., Harper, D., Smith, J. A., Fenn, M. A., Ferrare, R., Saide,
P. E., Chemyakin, E., and Müller, D.: Calibration of a high spectral resolution lidar using a Michelson interferometer, with data examples from ORACLES, Appl. Optics, 57, 6061-6075, 2018.

Chand, D., Wood, R., Anderson, T. L., Satheesh, S. K., and Charlson, R. J.: "Satellite-Derived Direct Radiative Effect of Aerosols Dependent on Cloud Cover", Nat. Geosci., 2, 181-184, https://doi.org/10.1038/ngeo437, 2009.

Cochrane, S., K., Schmidt, S., Chen, H., Pilewskie, P., Kittelman, S., Gore, W., Redemann, J., LeBlanc, S., Pistone, K., Platnick, S., Meyer, K., Ferrare, R., Burton, S., Hostetler, C., and Dobracki, A.: Aircraft-Derived Above-Cloud Aerosol Radiative Effects Based on ORACLES 2016 and ORACLES 2017 Experiments, in prepration, 2018.

Costantino, L. and Bréon, F.-M.: Aerosol indirect effect on warm clouds over South-East Atlantic, from co-located MODIS and CALIPSO observations, Atmos. Chem. Phys., 13, 69-88, https://doi.org/10.5194/acp-13-69-2013, 2013.

Cubison, M. J., Ortega, A. M., Hayes, P. L., Farmer, D. K., Day, D., Lechner, M. J., Brune, W. H., Apel, E., Diskin, G. S., Fisher, J. A., Fuelberg, H. E., Hecobian, A., Knapp, D. J., Mikoviny, T., Riemer, D., Sachse, G. W., Sessions, W., Weber, R. J., Weinheimer, A. J., Wisthaler, A., and Jimenez, J. L.: Effects of aging on organic aerosol from open biomass burning smoke in aircraft and laboratory studies, Atmos. Chem. Phys., 11, 12049-12064, https://doi.org/10.5194/acp-11-12049-2011, 2011.

Daniel, M., Lemonsu, A., Déqué, M., Somot, S., Alias, A., and Masson, V.: Benefits of explicit urban parametrization in regional climate modelling to study climate and city interactions, Clim. Dynam., 52, 2745-2764, https://doi.org/10.1007/s00382-018-4289$\mathrm{x}, 2019$.

Das, S., Harshvardhan, H., Bian, H., Chin, M., Curci, G., Protonotariou, A. P., Mielonen, T., Zhang, K., Wang, H., and Liu, X.: Biomass burning aerosol transport and vertical distribution over the South African-Atlantic region, J. Geophys. Res.-Atmos., 122, 6391-6415, https://doi.org/10.1002/2016JD026421, 2017.

Dee, D. P., Uppala, S. M., Simmons, A. J., Berrisford, P., Poli, P., Kobayashi, S., Andrae, U., Balmaseda, M. A., Balsamo, G., Bauer, P., Bechtold, P., Beljaars, A. C. M., van de Berg, L., Bidlot, J., Bormann, N., Delsol, C., Dragani, R., Fuentes, M., Geer, A. J., Haimbergere, L., Healy, S. B., Hersbach, H., Hólm, E. V., Isaksen, L., Kallberg, P., Köhler, M., Matricardi, M., McNally, A. P., Monge-Sanzf, B. M., Morcrette, J.-J., Park, B.-K., Peubey, C., de Rosnaya, P., Tavolato, C., Thépaut, J.-N., and Vitart, F.: The ERA-Interim reanalysis: configuration and performance of the data assimilation system, Q. J. Roy. Meteor. Soc., 137, 553597, https://doi.org/10.1002/qj.828, 2011.

De Graaf, M., Tilstra, L. G., Wang, P., and Stammes, P.: Retrieval of the aerosol direct radiative effect over clouds from spaceborne spectrometry, J. Geophys. Res., 117, D07207, https://doi.org/10.1029/2011JD017160, 2012.

De Graaf, M., Bellouin, N., Tilstra, L. G., Haywood, J., and Stammes, P.: Aerosol direct radiative effect of smoke over clouds over the southeast Atlantic Ocean from 2006 to 2009, Geophys. Res. Lett., 41, 7723-7730, https://doi.org/10.1002/2014GL061103, 2014.

Diamond, M. S., Dobracki, A., Freitag, S., Small Griswold, J. D., Heikkila, A., Howell, S. G., Kacarab, M. E., Podolske, J. R., Saide, P. E., and Wood, R.: Time-dependent entrainment of smoke presents an observational challenge for assessing aerosol- 
cloud interactions over the southeast Atlantic Ocean, Atmos. Chem. Phys., 18, 14623-14636, https://doi.org/10.5194/acp-1814623-2018, 2018.

Dubovik, O. and King, M. D.: A flexible inversion algorithm for retrieval of aerosol optical properties from Sun and sky radiance measurements, J. Geophys. Res., 105, 20673-20696, https://doi.org/10.1029/2000JD900282, 2000.

Dubovik, O., Smirnov, A., Holben, B. N., King, M. D., Kaufman, Y. J., Eck, T. F., and Slutsker, I.: Accuracy assessments of aerosol optical properties retrieved from Aerosol Robotic Network (AERONET) Sun and sky radiance measurements, J. Geophys. Res., 105, 9791-9806, https://doi.org/10.1029/2000JD900040, 2000.

Eck, T. F., Holben, B. N., Reid, J. S., Mukelabai, M. M., Piketh, S. J., Torres, O., Jethva, H. T., Hyer, E. J., Ward, D. E., Dubovik, O., Sinyuk, A., Schafer, J. S., Giles, D. M., Sorokin, M., Smirnov, A., and Slutsker, I.: A seasonal trend of single scattering albedo in southern African biomass-burning particles: Implications for satellite products and estimates of emissions for the world's largest biomass-burning source, J. Geophys. Res.-Atmos., 118, 6414-6432, https://doi.org/10.1002/jgrd.50500, 2013.

Feng, N. and Christopher, S. A.: Measurement-based estimates of direct radiative effects of absorbing aerosols above clouds, J. Geophys. Res.-Atmos., 120, 6908-6921, 2015.

Fierce, L., Bond, T. C., Bauer, S. E., Mena, F., and Riemer, N.: Black carbon absorption at the global scale is affected by particle-scale diversity in composition, Nat. Commun., 7, 12361, https://doi.org/10.1038/ncomms12361, 2016.

Formenti, P., Elbert, W., Maenhaut, W., Haywood, J., Osborne, S., and Andreae, M. O.: Inorganic and carbonaceous aerosols during the Southern African Regional Science Initiative (SAFARI 2000) experiment: Chemical characteristics, physical properties, and emission data for smoke from African biomass burning, J. Geophys. Res., 108, 8488, https://doi.org/10.1029/2002JD002408, 2003

Gelaro, R., McCarty, W., Suárez, M. J., Todling, R., Molod, A., Takacs, L., Randles, C. A., Darmenov, A., Bosilovich, M. G., and Reichle, R.: The modern-era retrospective analysis for research and applications, version 2 (MERRA-2), J. Climate, 30, 54195454, https://doi.org/10.1175/JCLI-D-16-0758.1, 2017.

Gordon, H., Field, P. R., Abel, S. J., Dalvi, M., Grosvenor, D. P., Hill, A. A., Johnson, B. T., Miltenberger, A. K., Yoshioka, M., and Carslaw, K. S.: Large simulated radiative effects of smoke in the south-east Atlantic, Atmos. Chem. Phys., 18, 15261-15289, https://doi.org/10.5194/acp-18-15261-2018, 2018.

Hair, J. W., Hostetler, C. A., Cook, A. L., Harper, D. B., Ferrare, R. A., Mack, T. L., Welch, W., Izquierdo, L. R., and Hovis, F. E.: Airborne High Spectral Resolution Lidar for profiling aerosol optical properties, Appl. Optics, 47, 6734-6752, https://doi.org/10.1364/AO.47.006734, 2008.

Haywood, J., Osborne, S. R., Francis, P. N., Keil, A., Formenti, P., Andreae, M. O., and Kaye, P. H.: The mean physical and optical properties of regional haze dominated by biomass burning aerosol measured from the C-130 aircraft during SAFARI 2000, J. Geophys. Res., 108, 8473, https://doi.org/10.1029/2002JD002226, 2003.

Heald, C. L., Ridley, D. A., Kroll, J. H., Barrett, S. R. H., Cady-Pereira, K. E., Alvarado, M. J., and Holmes, C. D.: Contrasting the direct radiative effect and direct radiative forcing of aerosols, Atmos. Chem. Phys., 14, 5513-5527, https://doi.org/10.5194/acp-14-5513-2014, 2014

Hodnebrog, O., Myhre, G., Forster, P. M., Sillmann, J., and Samset, B. H.: Local biomass burning is a dominant cause of the observed precipitation reduction in southern Africa, Nat. Commun., 7, 11236, https://doi.org/10.1038/ncomms11236, 2016.

Jethva, H., Torres, O., and Ahn, C.: A 12-year long global record of optical depth of absorbing aerosols above the clouds derived from the OMI/OMACA algorithm, Atmos. Meas. Tech., 11, 5837-5864, https://doi.org/10.5194/amt-11-5837-2018, 2018.

Johnson, B. T., Shine, K. P., and Forster, P. M.: The semi-direct aerosol effect: Impact of absorbing aerosols on marine stratocumulus, Q. J. Roy. Meteor. Soc., 130, 1407-1422, 2004.

Johnson, B. T., Haywood, J. M., Langridge, J. M., Darbyshire, E., Morgan, W. T., Szpek, K., Brooke, J. K., Marenco, F., Coe, H., Artaxo, P., Longo, K. M., Mulcahy, J. P., Mann, G. W., Dalvi, M., and Bellouin, N.: Evaluation of biomass burning aerosols in the HadGEM3 climate model with observations from the SAMBBA field campaign, Atmos. Chem. Phys., 16, $14657-$ 14685, https://doi.org/10.5194/acp-16-14657-2016, 2016.

Kahn, R. A. and Gaitley, B. J.: An analysis of global aerosol type as retrieved by MISR, J. Geophys. Res.-Atmos., 120, 4248-4281, https://doi.org/10.1002/2015JD023322, 2015.

Kar, J., Vaughan, M., Tackett, J., Liu, Z., Omar, A., Rodier, S., Trepte, C., and Lucker, P.: Swelling of transported smoke from savanna fires over the Southeast Atlantic Ocean, Remote. Environ., 211, 105-111, https://doi.org/10.1016/j.rse.2018.03.043, 2018.

Keil, A. and Haywood, J. M.: Solar radiative forcing by biomass burning aerosol particles during SAFARI 2000: A case study based on measured aerosol and cloud properties, J. Geophys. Res., 108, 8467, https://doi.org/10.1029/2002JD002315, 2003.

Labonne, M., Breon, F.-M., and Chevallier, F.: Injection height of biomass burning aerosols as seen from a spaceborne lidar, Geophys. Res. Lett., 34, L11806, https://doi.org/10.1029/2007GL029311, 2007.

Levelt, P. F., Hilsenrath, E., Leppelmeier, G., van den Oord, G., Bhartia, P. K., Tamminen, J., de Haan, J., and Veefkind, J.: Science Objectives of the Ozone Monitoring Instrument, IEEE T. Geosci. Remote, 44, 1199-1208, https://doi.org/10.1109/TGRS.2006.872336, 2006.

Lu, Z., Liu, X., Zhang, Z., Zhao, C., Meyer, K., Rajapakshe, C., Wu, C., Yang, Z., and Penner, J. E.: Biomass smoke from southern Africa can significantly enhance the brightness of stratocumulus over the southeastern Atlantic Ocean, P. Natl. Acad. Sci. USA, 115, 2924-2929 https://doi.org/10.1073/pnas.1713703115, 2018.

Mallet, M., Solmon, F., Roblou, L., Peers, F., Turquety, S., Waquet, F., Jethva, H., and Torres, O.: Simulation of Optical Properties and Direct and Indirect Radiative Effects of Smoke Aerosols Over Marine Stratocumulus Clouds During Summer 2008 in California With the Regional Climate Model RegCM, J. Geophys. Res.-Atmos., 122, 10288-10313, 2017.

Marticorena, B. and Bergametti, G.: Modeling the atmosphere dustcycle: 1 . Design of a soil-derived dust emission scheme, J. Geophys. Res., 100, 16415-16430, 1995.

Martin, G. M., Johnson, D. W., and Spice, A.: The measurement and parameterization of effective radius of droplets in warm stratiform clouds, J. Atmos. Sci., 51, 1823-1842, 1994. 
Masson, V., Le Moigne, P., Martin, E., Faroux, S., Alias, A., Alkama, R., Belamari, S., Barbu, A., Boone, A., Bouyssel, F., Brousseau, P., Brun, E., Calvet, J.-C., Carrer, D., Decharme, B., Delire, C., Donier, S., Essaouini, K., Gibelin, A.-L., Giordani, H., Habets, F., Jidane, M., Kerdraon, G., Kourzeneva, E., Lafaysse, M., Lafont, S., Lebeaupin Brossier, C., Lemonsu, A., Mahfouf, J.-F., Marguinaud, P., Mokhtari, M., Morin, S., Pigeon, G., Salgado, R., Seity, Y., Taillefer, F., Tanguy, G., Tulet, P., Vincendon, B., Vionnet, V., and Voldoire, A.: The SURFEXv7.2 land and ocean surface platform for coupled or offline simulation of earth surface variables and fluxes, Geosci. Model Dev., 6, 929-960, https://doi.org/10.5194/gmd-6-929-2013, 2013.

Mayer, B. and Kylling, A.: Technical note: The libRadtran software package for radiative transfer calculations - description and examples of use, Atmos. Chem. Phys., 5, 1855-1877, https://doi.org/10.5194/acp-5-1855-2005, 2005.

Meyer, K., Platnick, S., Oreopoulos, L., and Lee, D.: Estimating the direct radiative effect of absorbing aerosols overlying marine boundary layer clouds in the southeast Atlantic using MODIS and CALIOP, J. Geophys. Res.-Atmos., 118, 48014815, https://doi.org/10.1002/jgrd.50449, 2013.

Meyer, K., Platnick, S., and Zhang, Z.: Simultaneously inferring above-cloud absorbing aerosol optical thickness and underlying liquid phase cloud optical and microphysical properties using MODIS, J. Geophys. Res.-Atmos., 119, 5104-5114, https://doi.org/10.1002/2013JD021053, 2015.

Michou, M., Nabat, P., and Saint-Martin, D.: Development and basic evaluation of a prognostic aerosol scheme (v1) in the CNRM Climate Model CNRM-CM6, Geosci. Model Dev., 8, 501-531, https://doi.org/10.5194/gmd-8-501-2015, 2015.

Mlawer, E. J., Taubman, S. J., Brown, P. D., Iacono, M. J., and Clough, S. A.: Radiative transfer for inhomogeneous atmospheres: RRTM, a validated correlated-k model for the longwave, J. Geophys. Res., 102, 16663-16682, https://doi.org/10.1029/97JD00237, 1997.

Morcrette, J. J.: Description of the radiation scheme in the ecmwf model, Tech. rep, ECMWF, 1989.

Morcrette, J.-J., Boucher, O., Jones, L., Salmond, D., Bechtold, P., Beljaars, A., Benedetti, A., Bonet, A., Kaiser, J. W., Razinger, M., Schulz, M., Serrar, S., Simmons, A. J., Sofiev, M., Suttie, M., Tompkins, A. M., and Untch, A.: Aerosol analysis and forecast in the ECMWF Integrated Forecast System. Part I: Forward modelling, J. Geophys. Res., 114, D06206, https://doi.org/10.1029/2008JD011235, 2009.

Nabat, P., Somot, S., Mallet, M., Sevault, F., Chiacchio, M., and Wild, M.: Direct and semi-direct aerosol radiative effect on the Mediterranean climate variability using a coupled regional climate system model, Clim. Dynam., 44, 1127-1155, https://doi.org/10.1007/s00382-014-2205-6, 2015a.

Nabat, P., Somot, S., Mallet, M., Michou, M., Sevault, F., Driouech, F., Meloni, D., di Sarra, A., Di Biagio, C., Formenti, P., Sicard, M., Léon, J.-F., and Bouin, M.-N.: Dust aerosol radiative effects during summer 2012 simulated with a coupled regional aerosol-atmosphere-ocean model over the Mediterranean, Atmos. Chem. Phys., 15, 3303-3326, https://doi.org/10.5194/acp15-3303-2015, 2015b.

Nakajima, T. and King, M. D.: Determination of the Optical Thickness and Effective Particle Radius of Clouds from Reflected So- lar Radiation Measurements. Part 1: Theory, J. Atmos. Sci., 47, 1878-1893, 1990.

Nam, C., Bony, S., Dufresne, J.-L., and Chepfer, H.: The "too few, too bright" tropical low-cloud problem in CMIP5 models, Geophys. Res. Lett., 39, L21801, https://doi.org/10.1029/2012GL053421, 2012.

Nielsen, K. P., Gleeson, E., and Rontu, L.: Radiation sensitivity tests of the HARMONIE 37h1 NWP model, Geosci. Model Dev., 7, 1433-1449, https://doi.org/10.5194/gmd-7-1433-2014, 2014.

Ogren, J.: Comment on "Calibration and Intercomparison of FilterBased Measurements of Visible Light Absorption by Aerosols.", Aerosol Sci. Tech., 44, 589-591, 2010.

Oikawa, E., Nakajima, T., Inoue, T., and Winker, D.: A study of the shortwave direct aerosol forcing using ESSP/CALIPSO observation and GCM simulation, J. Geophys. Res.-Atmos., 118, 3687-3708, https://doi.org/10.1002/jgrd.50227, 2013.

Petrenko, M., Kahn, R., Chin, M., and Limbacher, J.: Refined use of satellite aerosol optical depth snapshots to constrain biomass burning emissions in the GOCART model, J. Geophys. Res.-Atmos., 122, 10983-11004, https://doi.org/10.1002/2017JD026693, 2017.

Platnick, S., Meyer, K. G., King, M. D., Wind, G., Amarasinghe, N., Marchant, B., Arnold, G. T., Zhang, Z. B., Hubanks, P. A., Holz, R. E., Yang, P., Ridgway, W. L., and Riedi, J.: The MODIS Cloud Optical and Microphysical Products: Collection 6 Updates and Examples From Terra and Aqua, IEEE T. Geosci. Remote, 55, 502-525, 2017.

Radu, R., Déqué, M., and Somot, S.: Spectral nudging in a spectral regional climate model, Tellus, 60A, 898-910, https://doi.org/10.1111/j.1600-0870.2008.00341.x, 2008.

Reid, J. S., Eck, T. F., Christopher, S. A., Koppmann, R., Dubovik, O., Eleuterio, D. P., Holben, B. N., Reid, E. A., and Zhang, J.: A review of biomass burning emissions part III: intensive optical properties of biomass burning particles, Atmos. Chem. Phys., 5, 827-849, https://doi.org/10.5194/acp-5-827-2005, 2005.

Rienecker, M. M., Suarez, M. J., Gelaro, R., Todling, R., Bacmeister, J., Liu, E., Bosilovich, M. G., Schubert, S. D., Takacs, L., Kim, G.-J., Bloom, S., Chen, J., Collins, D., Conaty, A., da Silva, A., Gu, W., Joiner, J., Koster, R. D., Lucchesi, R., Molod, A., Owens, T., Pawson, S., Pegion, P., Redder, C. R, Reichle, R., Robertson, F. R., Ruddick, A. G., Sienkiewicz, M., and Woollen, J.: MERRA: NASA's Modern-Era Retrospective Analysis for Research and Applications, J. Climate, 24, 3624-3648, https://doi.org/10.1175/JCLI-D-11-00015.1, 2011.

Rissler, J., Vestin, A., Swietlicki, E., Fisch, G., Zhou, J., Artaxo, P., and Andreae, M. O.: Size distribution and hygroscopic properties of aerosol particles from dry-season biomass burning in Amazonia, Atmos. Chem. Phys., 6, 471-491, https://doi.org/10.5194/acp-6-471-2006, 2006

Roebeling, R. A., Feijt, A. J., and Stammes, P.: Cloud property retrievals for climate monitoring: implications of differences between SEVIRI on METEOSAT-8 and AVHRR on NOAA-17, J. Geophys. Res., 111, D20210, https://doi.org/10.1029/2005JD006990, 2006.

Sakaeda, N., Wood, R., and Rasch, P. J.: Direct and semidirect aerosol effects of southern African biomass burning aerosol, J. Geophys. Res., 116, D12205, https://doi.org/10.1029/2010JD015540, 2011. 
Sayer, A. M., Munchak, L. A., Hsu, N. C., Levy, R. C., Bettenhausen, C., and Jeong, M.-J.: MODIS Collection 6 aerosol products: Comparison between Aqua's e-Deep Blue, Dark Target, and "merged" data sets, and usage recommendations, J. Geophys. Res.-Atmos., 119, 13965-13989, https://doi.org/10.1002/2014JD022453, 2014.

Sayer, A. M., Hsu, N. C., Bettenhausen, C., Lee, J., Redemann, J., Schmid, B., and Shinozuka, Y.: Extending "Deep Blue" aerosol retrieval coverage to cases of absorbing aerosols above clouds: Sensitivity analysis and first case studies, J. Geophys. Res.-Atmos., 121, 4830-4854, https://doi.org/10.1002/2015JD024729, 2016.

Sayer, A. M., Hsu, N. C., Lee, J., Kim, W. V., Burton, S., Fenn, M. A., Ferrare, R. A., Kacenelenbogen, M., LeBlanc, S., Pistone, K., Redemann, J., Segal-Rozenhaimer, M., Shinozuka, Y., and Tsay, S.-C.: Two decades observing smoke above clouds in the south-eastern Atlantic Ocean: Deep Blue algorithm updates and validation with ORACLES field campaign data, Atmos. Meas. Tech. Discuss., https://doi.org/10.5194/amt-2019-58, in review, 2019

Schulz, M., de Leeuw, G., and Balkanski, Y.: Sea-salt aerosol source functions and emissions, in: Emission of Atmospheric Trace Compounds, edited by: Granier, C., Artaxo, P., and Reeves, C. E., Kluwer Acad., Norwell, Mass., Springer Netherlands, 333359,2004

Seethala, C., Meirink, J. F., Horváth, Á., Bennartz, R., and Roebeling, R.: Evaluating the diurnal cycle of South Atlantic stratocumulus clouds as observed by MSG SEVIRI, Atmos. Chem. Phys., 18, 13283-13304, https://doi.org/10.5194/acp-18-132832018, 2018.

Shinozuka, Y., Saide, P. E., Burton, S. P., Zuidema, P., Ferrada, G. A., Mallet, M., Zhang, Y., Leung, R., Pfister, L., Ryoo, J.M., Howell, S. G., Freitag, S., Dobracki, A., Podolske, J. R., LeBlanc, S., Ferrare, R., Henze, D., Noone, D., Kacarab, M., Nenes, A., Stith, E. J., Bennett, J. R., Carmichael, G. R., Doherty, S. J., Wood, R., and Redemann, J.: Global and regional modeling of absorbing aerosols in the southeast Atlantic during ORACLES 2016: comparisons to new observations, in preparation, 2019.

Shipley, S. T., Tracy, D. H., Eloranta, E. W., Trauger, J. T., Sroga, J. T., Roesler, F. L., and Weinman, J. A.: High Spectral Resolution Lidar to Measure Optical-Scattering Properties of Atmospheric Aerosols .1. Theory and Instrumentation, Appl. Optics, 22, 3716-3724, https://doi.org/10.1364/AO.22.003716, 1983.

Slingo, A. and Schrecker, H. M.: On the shortwave radiative properties of stratiform water clouds, Q. J. Roy. Meteor. Soc., 108, 407-426, 1982.

Smith, R. N. B.: A scheme for predicting layer clouds and their water content in a general circulation model, Q. J. Roy. Meteor. Soc., 116, 435-460, 1990.

Stengel, M., Kniffka, A., Meirink, J. F., Lockhoff, M., Tan, J., and Hollmann, R.: CLAAS: the CM SAF cloud property data set using SEVIRI, Atmos. Chem. Phys., 14, 4297-4311, https://doi.org/10.5194/acp-14-4297-2014, 2014.

Stephens, G.: Radiation profiles in extended water clouds, II: Parametrization schemes, J. Atmos. Sci., 35, 2123-2132, 1978.

Stier, P., Schutgens, N. A. J., Bellouin, N., Bian, H., Boucher, O., Chin, M., Ghan, S., Huneeus, N., Kinne, S., Lin, G., Ma, X., Myhre, G., Penner, J. E., Randles, C. A., Samset, B., Schulz, M., Takemura, T., Yu, F., Yu, H., and Zhou, C.: Host model uncertain- ties in aerosol radiative forcing estimates: results from the AeroCom Prescribed intercomparison study, Atmos. Chem. Phys., 13, 3245-3270, https://doi.org/10.5194/acp-13-3245-2013, 2013.

Sun, Q., Wang, Z., Li, Z., Erb, A., and Schaaf, C. B.: Evaluation of the Global MODIS 30 Arc-Second Spatially and Temporally Complete Snow-Free Land Surface Albedo and Reflectance Anisotropy Dataset, Int. J. Appl. Earth Obs., 58, 36-49, 2017.

Torres, O., Tanskanen, A., Veihelman, B., Ahn, C., Braak, R., Bhartia, P. K., Veefkind, P., and Levelt, P.: Aerosols and surface UV products from OMI Observations: an overview, J. Geophys. Res., 112, D24S47, https://doi.org/10.1029/2007JD008809, 2007.

Tummon, F., Solmon, F., Liousse, C., and Tadross, M.: Simulation of the direct and semidirect aerosol effects on the southern Africa regional climate during the biomass burning season, J. Geophys. Res., 115, D19206, https://doi.org/10.1029/2009JD013738, 2010.

Vakkari, V., Beukes, J. P., Dal Maso, M., Aurela, M., Josipovic, M., and Van Zyl, P. G.: Major secondary aerosol formation in southern African open biomass burning plumes, Nat. Geosci., 11, 580-583, 2018.

van Marle, M. J. E., Kloster, S., Magi, B. I., Marlon, J. R., Daniau, A.-L., Field, R. D., Arneth, A., Forrest, M., Hantson, S., Kehrwald, N. M., Knorr, W., Lasslop, G., Li, F., Mangeon, S., Yue, C., Kaiser, J. W., and van der Werf, G. R.: Historic global biomass burning emissions for CMIP6 (BB4CMIP) based on merging satellite observations with proxies and fire models (1750-2015), Geosci. Model Dev., 10, 3329-3357, https://doi.org/10.5194/gmd-10-3329-2017, 2017.

Virkkula, A.: Correction of the Calibration of the 3-wavelength Particle Soot Absorption Photometer ( $3 \lambda$ PSAP), Aerosol Sci. Tech., 44, 706-712, https://doi.org/10.1080/02786826.2010.482110, 2010.

Wilcox, E. M.: Stratocumulus cloud thickening beneath layers of absorbing smoke aerosol, Atmos. Chem. Phys., 10, 1176911777, https://doi.org/10.5194/acp-10-11769-2010, 2010.

Xu, H., Guo, J. P., Ceamanos, X., Roujean, J. L., Min, M., and Carrer, D.: On the influence of the diurnal variations of aerosol content to estimate direct aerosol radiative forcing using MODIS data, Atmos. Environ., 141, 186-196, https://doi.org/10.1016/j.atmosenv.2016.06.067, 2016.

Zhang, J., Reid, J. S., Christensen, M., and Benedetti, A.: An evaluation of the impact of aerosol particles on weather forecasts from a biomass burning aerosol event over the Midwestern United States: observational-based analysis of surface temperature, Atmos. Chem. Phys., 16, 6475-6494, https://doi.org/10.5194/acp16-6475-2016, 2016.

Zuidema, P., Redemann, J., Haywood, J., Wood, R., Piketh, S., Hipondoka, M., and Formenti, P.: Smoke and clouds above the southeast Atlantic: Upcoming field campaigns probe absorbing aerosols impact on climate, B. Am. Meteorol. Soc., 97, 11311135, 2016.

Zuidema, P., Sedlacek, A., Flynn, C., Springston, S., Delgadillo, R., Zhang, J., Aiken, A., and Muradyan, P.: The Ascension Island boundary layer in the remote southeast Atlantic is often smoky, Geophys. Res. Lett., 45, 4456-4465, https://doi.org/10.1002/2017GL076926, 2018. 